\title{
Perspectiva geográfica de la caza en Mallorca
}

\author{
Hunting in Mallorca from a geographical point of view
}

\author{
Antoni Barceló Adrover ${ }^{1}$ \\ Miquel Grimalt Gelabert ${ }^{2}$ \\ Jaume Binimelis Sebastián ${ }^{3}$
}

\section{Resumen}

A partir de datos oficiales de titulares de licencias de caza y espacios cinegéticos proporcionados por el Servei de Caça del Departament de Desenvolupament Local del Consell de Mallorca se realiza un estudio de detalle sobre las implicaciones sociales y territoriales de la actividad cinegética en la isla. Por una parte, se analiza la distribución, la edad, el género, la tipología de licencia y el origen de las personas que practican la caza y, por otra parte, se examina la categoría, la localización y la extensión de los espacios cinegéticos y de los refugios de fauna. Tomando como referencia las demarcaciones administrativas y en función del índice de superficie de terreno de caza por persona, se establece una categorización en municipios demandantes, ofertantes o equilibrados en cuanto a espacios de caza. Finalmente, se valora el devenir reciente de la caza, muy condicionado por cambios de uso del suelo y de cuestionamiento de la actividad, por lo cual resulta de especial importancia la planificación cinegética.

Palabras clave: Caza; Mallorca; licencias de caza; espacios cinegéticos; planificación cinegética.

\begin{abstract}
According to the official data about the holders of hunting licenses and hunting areas provided by the hunting service of the Local Development Department - Consell de Mallorca, a detailed study is carried out on the social and territorial implications of the hunting activity on the island. Firstly, the spatial distribution, age, gender, type of license and origin of the hunters are analysed and, secondly, the category, location and extension of the hunting and non-hunting areas are examined. Administrative boundaries are used as a reference and depending on the hunting land area index per person, a categorization is established in municipalities that are requesting, bidding for or are balanced in terms of hunting spaces. Finally, the hunting situation is evaluated, which is currently conditioned by changes in land use and social questioning about the activity. In this sense, hunting planning is fundamental.
\end{abstract}

Keywords: Hunting; Mallorca; hunting licences; hunting areas; hunting planning.

\section{Introducción}

\subsection{El área de estudio}

El análisis de los aspectos sociales y territoriales de la caza en Mallorca constituye el objetivo del presente estudio.

Mallorca es la isla más extensa del archipiélago balear $\left(3.626 \mathrm{~km}^{2}\right)$, situada en la cuenca mediterránea occidental, concretamente al este de la Península Ibérica. Se trata de un territorio relativamente llano,

\footnotetext{
1 Consell de Mallorca. Departamento de Geografía, Universitat de les Illes Balears, España. barceloadrover@yahoo.es

2 Departamento de Geografía, Universitat de les Illes Balears, España. miquel.grimalt@uib.es

3 Departamento de Geografía, Universitat de les Illes Balears, España. jaume.binimelis@uib.es
} 
aun cuando la planicie central (es Pla) se encuentra comprendida entre dos áreas montañosas, la Serra de Tramuntana en la parte noroccidental, con alturas superiores a los $1.000 \mathrm{~m}$. y las Serres de Llevant en la zona suroriental, con cimas que alcanzan los $500 \mathrm{~m}$.

El clima insular es mediterráneo litoral, caracterizado por temperaturas moderadas a lo largo del año y una pluviometría con un mínimo estival muy marcado que viene seguido de un máximo otoñal, habiendo grandes contrastes de la lluvia anual entre las áreas montañosas septentrionales (donde se alcanzan los $1.400 \mathrm{~mm}$ ) y el litoral meridional (donde se reduce a poco más de $300 \mathrm{~mm}$ ).

La vegetación, típicamente mediterránea presenta extensas maquias de acebuche (Cneoro-Ceratonietum) dominantes en las comarcas meridionales y orientales, en tanto que el encinar (Cyclamini-Quercetum ilicis) constituye el bosque predominante en las áreas septentrionales y centrales.

Las zonas montañosas presentan asociaciones propias y albergan endemismos de gran valor botánico especialmente en las partes culminares y en los acantilados. A pesar de su poca significación fitosociológica el pino blanco (Pinus halepensis) constituye la especie arbórea más abundante, cubriendo áreas potencialmente correspondientes a encinares o acebuchales.

La fauna terrestre está constituida por especies mediterráneas, con un número reducido de taxones y ausencia de grandes mamíferos, al estar condicionada por las circunstancias de insularidad extrema y las introducciones de nuevas especies por la relativamente reciente llegada de población humana (hace unos 4.000 años). El mayor herbívoro es la cabra salvaje mallorquina (Capra aegagrus / hircus cf.dorcas), presente en la isla desde el inicio del poblamiento humano, y la cabra asilvestrada (Capra hircus) de origen doméstico reciente.

Figura 1. Mapa de municipios y comarcas de Mallorca

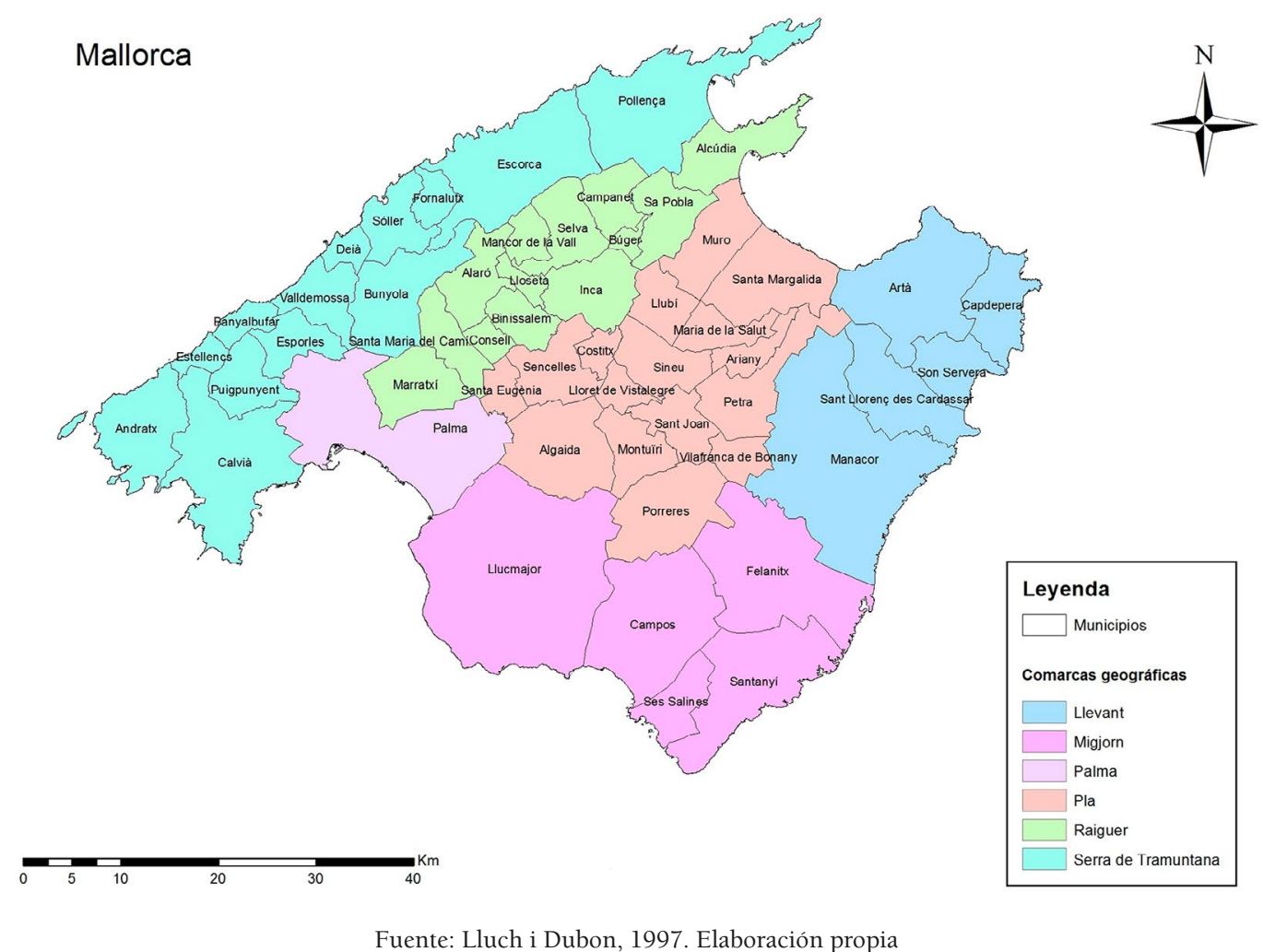

La isla cuenta con una población de 861.430 habitantes en 2016 (Instituto de Estadística de las Islas Baleares [IBESTAT], 2017), lo que supone una densidad de 237,5 habitantes $/ \mathrm{km}^{2}$, que se distribuyen de forma desigual por los 53 municipios (Figura 1). La capital, Palma, concentra a prácticamente la mitad de los residentes $(46,77 \%)$. En términos sectoriales, se constata una marcada terciarización de la población activa en torno al turismo estival, frente a un sector secundario decadente centrado en la construcción y una muy escasa dedicación al sector primario, estadísticamente residual. Históricamente la agricultura 
ha conformado la sociedad y el hábitat tradicional, al tiempo que ha modificado el medio físico, conformando buena parte del paisaje insular. En el contexto esencialmente agroganadero se ha pasado de un modelo productivista autosuficiente a un escenario mayoritariamente desagrarizado y dependiente del exterior debido a la insularidad. La aplicación de medidas emanadas de la Política Agraria Comunitaria ha contribuido a un fuerte retroceso del sector lechero y de los cultivos asociados, a la extensificación de los sistemas agrarios, a la progresiva concentración de las explotaciones y a un gradual abandono de muchas tierras de labor. A la par, han aumentado las extensiones cerealistas, las parcelas destinadas a barbechos sociales, los espacios forestales, la agricultura ecológica y las actividades estratégicas de diversificación como el turismo rural. Estos cambios han favorecido a las especies más adaptables (paloma torcaz, liebre o cabras, por ejemplo) mientras que otras han experimentado limitaciones en sus hábitats (como es el caso de la codorniz o la tórtola salvaje). La mayor parte de los espacios de aprovechamiento cinegético insulares han experimentado reducciones en la superficie útil de caza debido a la emergencia de nuevos usos en el medio rural, sobretodo residencial, mientras que el colectivo de cazadores asume de cada vez más un importantísimo papel en la gestión ambiental de un entorno postproductivista. A grandes rasgos, la estructura socioeconómica y el modelo territorial actual responden al desarrollo turístico experimentado a partir de la segunda mitad del siglo XX. El aumento del peso específico de la población urbana, la edificación masiva de zonas litorales, el amplio desarrollo de infraestructuras de comunicación, la regresión de las prácticas agrícolas y ganaderas y la rururbanización generalizada en la mayor parte del territorio son algunos de los aspectos más significativos de un escenario insular modelado por la actividad turística.

El territorio insular se corresponde con un mosaico paisajístico en el que alternan espacios naturales de gran interés ambiental con áreas altamente humanizadas. La caza es una práctica tradicional con un importante arraigo en Mallorca que se desarrolla en espacios naturales y rurales, que entra en conflicto con la creciente terciarización económica, la urbanización de amplias áreas y la progresiva introducción de estilos de vida urbanos. Cuenta con un importante despliegue normativo que regula la actividad, destacando la Ley 6/2006 de 12 de abril, balear de caza y pesca fluvial y el reglamento 1/2012 del Consell Insular de Mallorca por el cual se regulan las vedas y los recursos cinegéticos, aprobado definitivamente el 9 de febrero de 2012, y otras normas asociadas a la gestión cinegética como son, entre otras, el decreto $72 / 2004$, de 16 de julio, por el cual se regulan los planes técnicos de caza y los refugios de caza en las Islas Baleares y el decreto 91/2006, de 26 de octubre, de regulación de las poblaciones caprinas, de ordenación del aprovechamiento cinegético de la cabra salvaje mallorquina y de modificación de los planes técnicos.

\subsection{Antecedentes: datos sobre la práctica de la caza a diversas escalas, aportaciones geográficas en el contexto nacional y revisión de estudios sobre aspectos sociales y territoriales}

La práctica cinegética ha suscitado el interés de las investigaciones geográficas atendiendo a sus múltiples implicaciones sociales, territoriales y ambientales. Actualmente la caza juega un importante papel en la gestión y conservación de los espacios rurales en sentido amplio, al ser una actividad fundamentada en el aprovechamiento sostenible de los recursos cinegéticos, que contribuye positivamente en la conservación de los hábitats y ecosistemas y supone una importante dinamización económica en entornos frágiles.

A nivel mundial, según datos de 2005 del World Forum of the Future Sport Shooting Activities (WFSA) (Bernard Danzberger, 2009), se recuentan más de 56.000 .000 cazadores y tiradores deportivos (Tabla 1) que se distribuyen de la manera siguiente:

Tabla 1. Número de cazadores y tiradores deportivos en el mundo

\begin{tabular}{|c|c|}
\hline País / región & Número \\
\hline Estados Unidos & 26.000 .000 \\
\hline Unión Europea & 7.700 .000 \\
\hline Canadá & 7.500 .000 \\
\hline Otros países & 14.900 .000 \\
\hline Total & 56.100 .000 \\
\hline
\end{tabular}

Fuente: Bernard, 2009 
España, con 980.000 cazadores es, tras Francia, el segundo país europeo con mayor número de practicantes (Federation of Associations for Hunting and Conservation of the EU [FACE], 2010) y cuenta con 43.078.467 hectáreas acotadas lo que supone el 85,14\% del territorio nacional (Ministerio de Agricultura y Pesca, Alimentación y Medio Ambiente [MAPAMA], 2013). Se distinguen más de 50 especies cinegéticas desigualmente repartidas por las diferentes comunidades autónomas. Asimismo, España es también un importante destino internacional para los turistas de caza, sobretodo europeos y estadounidenses, atendiendo a la calidad y singularidad de sus recursos cinegéticos (Rengifo Gallego, 2009). En términos económicos, la caza genera 3.635.756.996 € y unos 54.000 empleos (Garrido Martín, 2012).

En el contexto de las Islas Baleares, en 2008, el número de licencias de caza ascendía a más de 27.000 y el $71,97 \%$ del territorio estaba acotado con más de 1.900 cotos (Barceló, 2013), (Tabla 2). Hay un total de 27 especies cinegéticas y como muestra del arraigo de esta actividad entre la población insular se ha descrito un notable número de modalidades de caza exclusivas del territorio insular, como la caça amb cans eivissencs (caza con una raza de podencos propios de las Islas Baleares), caça de tords a coll (captura de zorzales mediante redes accionadas manualmente en zonas de paso), caça de la perdiu amb reclam i bagues (ejercida sobre perdices, que se atraen con un ave de reclamo y se capturan vivas a lazo) y caça de cabres amb llaç (caza de cabras con perros y lazo). Otro dato que confirma la tradición cinegética es la presencia de hasta 4 razas caninas venatorias: el ca eivissenc, el ca rater, el ca mè mallorquí y el ca de conills de Menorca (Bover Pujol y Rosselló Vaquer, 2016).

Tabla 2. Licencias y cotos de caza en las Islas Baleares en 2008

\begin{tabular}{|l|l|l|l|l|l|}
\hline Isla & Licencias & Número de cotos & $\begin{array}{l}\text { Superficie } \\
\text { acotada (Ha) }\end{array}$ & $\begin{array}{l}\text { Superficie media } \\
\text { de los cotos (Ha) }\end{array}$ & $\begin{array}{l}\text { \% de territorio } \\
\text { acotado }\end{array}$ \\
\hline Mallorca & $>22.500$ & 1.406 & $268.659,15$ & 191,08 & 74,09 \\
\hline Menorca & 2.560 & 475 & $54.092,84$ & 113,88 & 78,38 \\
\hline Ibiza & 2.005 & 35 & $34.613,36$ & 988,95 & 61,04 \\
\hline Formentera & 128 & 5 & $3.518,85$ & 703,77 & 45,69 \\
\hline TOTAL & $>27.000$ & 1.921 & $360.884,2$ & 187,86 & 71,97 \\
\hline
\end{tabular}

Fuente: Barceló Adrover, 2013.

La actividad cinegética ha sido objeto de investigación desde el campo de la geografía, aunque el volumen de artículos y publicaciones es escaso, considerando la dimensión social y territorial de la actividad cinegética. La geografía cinegética, como segmento de la Biogeografía, como parte de la Geografía Agraria o como manifestación de la Geografía del Ocio es tarea compleja e interesante, y en España se cuenta con atisbos e hipótesis interesantes y son patentes la falta de estudios básicos al respecto en muchas comunidades (López Ontiveros, 1991). Independientemente de valores y cuestiones histórico-filosóficas, el aprovechamiento de los recursos cinegéticos presenta un innegable trasfondo social y territorial que en muchas ocasiones resulta desconocido. Además, en España, la caza es una actividad muy importante y su estudio no puede quedar al margen de la reflexión del geógrafo y de otros científicos sociales (López Ontiveros, 1994).

En el conjunto de España, entre 1978 y 2015, se recuentan un total de 150 publicaciones sobre geografía y caza destacando la irregularidad temporal de las mismas y la inexistencia de líneas de investigación claras y continuadas. En las últimas décadas, los estudios sobre geografía cinegética se han incrementado considerablemente en la mitad sur peninsular y en Baleares, mientras que en otras regiones los trabajos son bastante escasos. Las referencias bibliográficas estudiadas pertenecen a las Universidades de Córdoba (López Ontiveros, Mulero Mendigorri y Valle Buenestado), Autónoma de Madrid (Martínez Garrido), Jaén (Araque y Crespo), Extremadura (Rengifo Gallego y Alvarado Corrales) e Islas Baleares (Barceló Adrover), y han centrado sus estudios principalmente en las comunidades de Andalucía, Castilla-La Mancha, Extremadura y Baleares. Estos nueve autores han intervenido en prácticamente el $80 \%$ del total de las obras estudiadas. Las temáticas dominantes en España son, por una parte, caza y Geografía Agraria, línea de investigación muy fecunda en el campo de la Geografía Rural, y, por otra, la geografía de los espacios cinegéticos, que examina las características sociales y territoriales de la caza en un marco espacial determinado (Barceló Adrover, Grimalt Gelabert y Binimelis Sebastián, 2017). 
En efecto, los elementos sociales y territoriales de la actividad cinegética, es decir, número de personas cazadoras y hectáreas acotadas, son aspectos cardinales de carácter geográfico para contextualizar la práctica cinegética a cualquier escala, ya sea local, regional, estatal o internacional. En Baleares, existen algunos trabajos de esta índole principalmente sobre Mallorca (Brunet Estarellas, 1988; Aguilar y Mayol, 1988; Barceló Adrover, 2009; Murray Mas, 2012 y Barceló Adrover, 2015a) y Menorca (Pons Muñoz, 1995 y Barceló Adrover, 2015b) en los cuales se aportan datos de cazadores y territorios acotados en diferentes años. En la misma línea se ha trabajado regionalmente en espacios de alto interés cinegético como la Sierra Morena cordobesa (Mulero Mendigorri, 1993, 1995) o Extremadura (Rengifo Gallego y Sánchez Martín, 2016). A nivel nacional, diversos autores (López Ontiveros, 1981, 1991, 1994; López Ontiveros y García Verdugo, 1991 y Martínez Garrido, 2009) han manejado macrodatos sobre licencias de caza y espacios cinegéticos, e incluso en base a estos indicadores se acuñó el concepto de Boom Cinegético (López Ontiveros, 1981) para definir el espectacular aumento de la caza después de la Guerra Civil. En este sentido, existen tres indicadores claros que escenifican el aumento de la actividad cinegética en España a lo largo de la segunda mitad del siglo XX (López Ontiveros, 1991). Son los siguientes:

A) Licencias de caza. De 1940 a 1987, las licencias de caza pasan de 139.918 en 1946 a 1.283 .353 en 1987. En total, el incremento es superior al millón de licencias.

B) Espacios cinegéticos. En 1986, las tierras sometidas a régimen especial según la Ley de Caza, suponen un $78,69 \%$ de la superficie nacional.

C) Significado económico de la caza. En 1985 (Metra Seis, 1985) la generación de renta por la caza se calcula en cerca de 80.000 millones de pesetas y los puestos de trabajo derivados en algo más de 15.000. No obstante, cabe indicar que estos datos presentan algunas objeciones atendiendo a aspectos derivados de la muestra y/o de la extrapolación.

En el ámbito nacional no se han localizado trabajos geográficos de actualización de los referenciados que sirven de punto de partida para el presente estudio ni tampoco afines en cuanto a metodología, si bien son frecuentes las publicaciones regionales desde diversas ópticas disciplinares con patrones de análisis de carácter socioeconómico (Econométrica Investigación social, 2009, Fundación Caza sostenible y biodiversidad (FUNCASBIOD), 2016 o González Arenas, Arias de Reyna Martínez y Ruiz Avilés, 2004) o que utilizan variables sociales o territoriales para centrar las investigaciones (Serrano García, 2005; Rengifo Gallego, 2012; Monge Gómez, 2012 o Crespo Guerrero, 2013).

No obstante, recientemente se ha publicado un completo y actualizado estudio del impacto social y económico de la caza en España en relación al 2016 (Andueza, Lambarri, Urda, Prieto, Villanueva y Sánchez García, 2018a) que evalúa la actividad cinegética principalmente desde las perspectivas económicas, sociales y ambientales. Según este trabajo, la caza moviliza en España 5.470 millones de $€$, contribuye al mantenimiento de 186.758 empleos anuales y genera el 0,3\% del PIB nacional. En términos sociales, en el 2013 se expidieron 848.243 licencias de caza y en el ámbito territorial, en el 2015, el 87\% de la superficie nacional se encuentra acotada mediante más de 32.000 cotos (Andueza et al., 2018 a partir de datos del MAPAMA).

A nivel europeo, por poner algunos ejemplos, Francia dispone de estudios muy pormenorizados a nivel social sobre el perfil del cazador (Pinet, 1993) y en Suiza, el Cantón de la Caza, la Pesca y la Fauna, presenta anualmente unas depuradas estadísticas sobre especies y capturas orientadas a mejorar la planificación cinegética (www.vs.ch). En el continente americano, Estados Unidos publica cada quinquenio una extensa encuesta a nivel nacional sobre pesca, caza y actividades recreativas asociadas a la vida silvestre (www.census.gov/prod/www/fishing.html).

\subsection{Objetivos}

El objetivo principal del presente estudio consiste en analizar las implicaciones territoriales de la actividad cinegética en Mallorca, definiendo a escala municipal la distribución de la oferta y demanda de la misma, elaborando una clasificación municipal a partir de criterios fundamentados en indicadores básicos de ámbito social y territorial. Como objetivos secundarios, aunque preceptivos y conducentes a conseguir el análisis territorial propuesto, se plantean analizar diferentes características de los titulares de licencias de caza (recuento del total de titulares de licencias de caza, número total de licencias, localidad de residencia de los titulares de las mismas, presencia de cazadores foráneos, edad y género de las perso- 
nas que cazan) y de los espacios cinegéticos y no cinegéticos presentes en la isla (tipologías de espacios en dónde se puede cazar y de aquellos dónde esta actividad está limitada, recuento, extensión y localización).

Se supone que en Mallorca se pueden distinguir comportamientos contrastados entre los municipios en función de la disponibilidad de terrenos de caza por cazador residente, pudiéndose diferenciar entre municipios ofertantes (que tienen una elevada superficie acotada por cazador local), demandantes (que presentan un gran número de licencias en relación al espacio de caza disponible) y equilibrados (en dónde los parámetros mantienen una relación equitativa).

La hipótesis de partida se centra en que, en un espacio insular con una amplia variedad paisajística debida a la combinación de factores físicos y humanos, y con alta densidad de población tiene que haber diferencias importantes entre demarcaciones municipales en lo que se refiere a terrenos de caza disponibles.

Con base a un índice entre disponibilidad territorial y el factor social debe de ser posible clasificar los municipios en cuanto a presión cinegética. Esta clasificación puede tener un notable interés aplicado, en relación a la planificación de la caza llevada a cabo por la administración autonómica balear, con los planes técnicos de caza mencionados en la Ley 6/2006 de caza y pesca fluvial (BOIB, núm. 61, 27/04/2006 y en la Ley 42/2007, de patrimonio natural y biodiversidad (BOE núm. 299, 14/12/2007).

A una escala más amplia, tiene que ser posible discernir una clara tendencia evolutiva del número de personas que practican la caza y de los espacios acotados, que a priori puede intuirse a la baja en los dos casos atendiendo a los actuales factores urbanos, de pérdida de identidad con el medio rural y de cambio de usos del suelo.

En el trasfondo de estas cuestiones gravita el papel del sector cinegético en la aplicación de estrategias de desarrollo rural y conservación ambiental.

\section{Metodología}

La metodología se basa en el análisis de datos sobre titulares de licencias de caza, espacios cinegéticos y espacios no cinegéticos (refugios de fauna) de los municipios de Mallorca en el año 2013. Se han utilizado los últimos datos depurados y disponibles facilitados por el Servicio de Caza del Departament de Desenvolupament Local del Consell de Mallorca, administración competente en materia cinegética. En el caso de los titulares de licencias de caza comprende todo el año 2013 y para los espacios cinegéticos son de 1 de enero de 2013.

La información estadística proporcionada por el Consell de Mallorca se ha estructurado en una compleja base de datos relacional, sobre la cual se han realizado los diferentes cálculos, utilizando la aplicación Microsoft Excel, que reflejan los indicadores básicos de la actividad: número de titulares de licencia de caza y número de hectáreas acotadas, por municipio. Hay que resaltar que un aspecto diferencial de este trabajo es que se depuran el número total de personas que cazan o titulares de licencia de caza, diferenciándose claramente de la mayoría de estudios que citan licencias de caza a sabiendas que una persona puede disponer de más de una de dichas licencias. Atendiendo a la calidad de los campos asociados a cada indicador se ha podido extraer el total de licencias de caza, la edad y el género de los titulares y, en el caso de los cotos / refugios de fauna, el número existente en cada municipio y su tipología.

Complementariamente, se han utilizado datos de población de 2013 obtenidos del IBESTAT (2013) al objeto de poder cuantificar el porcentaje de personas cazadoras en el conjunto de la sociedad insular. Mediante las tipologías de licencia de caza y analizando los formatos de los documentos de identidad de cada persona se han conseguido discernir y contabilizar los cazadores no nacionales.

La información cuantitativa sobre las variables territoriales se ha calculado a partir de la cartografía original proporcionada por la administración (Servicio de Caza del Departament de Desenvolupament Local del Consell de Mallorca) y utilizando sistemas de información geográfica, tratándose por tanto de una información estadística original e inédita. La capa vectorial de núcleos urbanos se refiere a superficies edificadas (núcleos urbanos, zonas deportivas, aeropuertos,...), y se ha utilizado para poder valorar y representar con exactitud y por defecto, una vez superpuestos los cotos y refugios de fauna, los terrenos popularmente conocidos como libres. Estos terrenos libres bien pueden ser cinegéticos (si disponen de plan técnico propio o si el ayuntamiento en cuestión se adhieren al plan marco que elabora anualmente el Consell de Mallorca) o no cinegéticos (no disponen de planificación cinegética). A efectos del presente estudio, este terrenos se consideran cinegéticos, de ahí la denominación de terrenos susceptibles de apro- 
vechamiento cinegético a los terrenos cinegéticos más los terrenos libres. Cabe considerar que esta capa no representa las vías de comunicación ni las viviendas o edificios aislados en suelo rústico, que a efectos de práctica cinegética son zonas de seguridad. El análisis geográfico y la representación cartográfica se ha realizado con el programa ArcGIS de ESRI, concretamente con la aplicación ArcMap v.10., y entre otros, se ha obtenido un mapa de Mallorca temático estructurado en espacios cinegéticos y espacios no cinegéticos.

Es preciso indicar que los datos de titulares de licencias de caza publicados en este trabajo presentan mejoras respecto de los publicados anteriormente (Barceló Adrover, 2015a y 2015b). Esto se debe a tres razones principales. Primeramente, el año 2010 tuvo lugar el traspaso de competencias en materia de caza desde el gobierno autónomo de las Islas Baleares a los respectivos consejos insulares, lo que llevó aparejados cambios en los sistemas de tratamiento y volcado de datos. En segundo lugar, desde hace aproximadamente una década se emiten licencias de caza por uno, dos y tres años, hecho que ha introducido nuevas variables dificultando el recuento de las licencias activas en un momento determinado. Finalmente, y de forma definitiva al ser detectados algunos errores metodológicos en recuento de titulares, el Servicio de Caza del Departament de Desenvolupament Local del Consell de Mallorca, durante los últimos años ha realizado los ajustes necesarios tanto en el software de expedición de licencias de caza como en la formación del personal para poder disponer de datos muy precisos sobre titulares y licencias en un periodo determinado. Así pues, los datos que se presentan en los próximos apartados han sido totalmente validados metodológicamente por la administración competente.

La obtención de información precisa sobre el total de cazadores y de espacios cinegéticos resulta fundamental para enmarcar los estudios cinegéticos y realizar una correcta interpretación de la realidad a cualquier escala de trabajo. Aunque existan datos publicados por las administraciones y / o entidades venatorias, se ha detectado una falta de actualización de las estadísticas oficiales en España (González Arenas, Arias de la Reyna Martínez y Ruíz Avilés, 2004; Martínez Garrido, 2009) —error repetido tradicionalmente- y además la estadística oficial de la caza es incompleta, se encuentra dispersa y no es homogénea (Martínez-Jauregui, Arenas y Herruzo, 2011). Por una parte, el número de licencias de caza no refleja el número total de cazadores, al poder concurrir en una misma persona más de una licencia, bien sea para practicar diferentes modalidades o para cazar en diferentes comunidades autónomas. Además, y aunque las licencias están sujetas a tasas y son personales e intransferibles, los datos transferidos por las comunidades autónomas, provincias o consejos insulares al MAPAMA no siempre responden a un mismo estándar metodológico. La normativa diversificada a nivel territorial conlleva que en algunas regiones se emitan licencias por uno, dos o tres años, no coincidiendo las licencias emitidas en un año con las vigentes para dicho período. Por otra parte, y en lo que a terrenos cinegéticos se refiere, los datos aportados por las Comunidades Autónomas no son siempre exactos (por ejemplo, en el año 2010, en la estadística del Ministerio faltan los datos de terrenos cinegéticos de 4 comunidades autónomas). No obstante, la progresiva incorporación de complejos programas de gestión de licencias y herramientas SIG en las administraciones competentes en caza, junto con criterios de recopilación de datos concisos, supone una importante mejora en este campo.

En el caso que nos ocupa sobre Mallorca, por lo que se refiere al apartado social de la caza, se han utilizado únicamente datos de titulares (es decir, personas físicas) de licencias de caza a partir del identificador DNI (para evitar duplicados) y no simplemente licencias de caza. Este es uno de los puntos más innovadores del trabajo, ya que en la mayoría de investigaciones similares es muy frecuente utilizar licencias de caza, aceptando implícitamente dobles contabilizaciones. En el apartado territorial se ha hecho uso de la capa vectorial de espacios cinegéticos, revisando espacialmente las duplicidades mediante el identificador número de matrícula de coto y corrigiendo eventuales solapamientos entre acotados.

Así pues, del producto obtenido entre el número de titulares de licencias de caza y el número de hectáreas acotadas se categorizan los municipios en ofertantes, demandantes y equilibrados. Para establecer los límites entre las diversas categorías, se ha tomado como referencia el decreto 72/2004 por el cual se regulan los planes técnicos de caza y los refugios de caza de las Islas Baleares. Según dicha norma el número de cazadores por hectárea en un coto con plan técnico de régimen general (que son la mayoría) es de 3 en relación a las 30 primeras hectáreas o fracción; a partir de este mínimo se incrementa el número de usuarios permitidos en un cazador más por cada 20 hectáreas o fracción. Consecuentemente en el presente estudio se establece como referencia el intervalo óptimo de entre 15 y 25 hectáreas por cazador. La categorización resultante se define en base a los siguientes intervalos de clase: 
$\cdot \geq 15$ y $\leq 25$ ha cazador: municipio equilibrado

$\cdot>7,5$ ha y < a 15 ha cazador: municipio demandante

- $\leq$ a 7,5 ha cazador: municipio gran demandante

- >25 ha y a $50 \leq$ ha cazador: municipio ofertante

- > a 50 ha cazador: municipio gran ofertante

Los municipios equilibrados serán aquellos en que cada cazador dispone de entre 15 y 25 hectáreas para cazar, los municipios demandantes son los que cada cazador tiene menos de 15 hectáreas de terreno de caza y los municipios ofertantes son aquellos en que cada persona practicante de la actividad cinegética dispone de más de 25 hectáreas aptas para la misma. Para afinar aún más la clasificación, se han establecido dos categorías extremas de municipios: grandes demandantes (valor demandante / 2) y grandes ofertantes (valor ofertante x 2), respectivamente.

En definitiva, esta aportación pretende realizar un estudio de base regional sobre la actividad cinegética en el ámbito territorial de Mallorca siguiendo similitudes con la Ley 7/1985, de 2 de abril, reguladora de las Bases de Régimen Local, la cual establece que los elementos básicos del municipio son el territorio, la población y la organización. Así pues, en función de la normativa y la organización establecida por la Ley 6/2006 de 12 de abril balear de caza y pesca fluvial, se analiza en detalle el padrón de titulares de licencias de caza, se evalúa el territorio insular sometido a régimen cinegético y sus diferentes figuras y se extraen indicadores de cazadores por hectárea que permitan categorizar los municipios en cuanto a su capacidad de carga, además de poder realizar comparativas con otros lugares a partir de estadísticas oficiales.

\section{Resultados}

\subsection{Aspectos sociales de la caza}

Para realizar un análisis social de la caza en Mallorca se ha determinado el número total de cazadores existentes, su localidad de residencia, la edad, la distribución por sexos, el número de cazadores en relación con el total de población, el tipo de licencias más frecuentes y la importancia del turismo cinegético.

\subsubsection{Titulares de licencia de caza}

A partir de los datos proporcionados por el Servicio de Caza del Departament de Desenvolupament Local del Consell de Mallorca, se han contabilizado 18.236 titulares de licencias de caza en Mallorca (2013). Existe una alta correlación entre titulares de licencias y la población y la extensión de las demarcaciones municipales (Tabla 3).

Si se realiza una comparativa entre Palma (capital insular) y el resto de la isla, la primera con un $46,04 \%$ de la población aporta el $24,18 \%$ de los titulares de licencias de caza mientras que el resto de municipios con un $53,96 \%$ de la población total aporta el $73,96 \%$. Dejando aparte a la capital, las cifras más altas de titulares de licencias de caza en términos absolutos las encontramos en los municipios con mayor número de residentes y más extensos, situados en el sur y sureste de la isla (Llucmajor, Manacor, Felanitx, Campos y Santanyí) y los principales núcleos del Raiguer - pie de monte de la sierra de Tramuntana- (Inca y Marratxí) y de la zona montañosa propiamente dicha (Sóller y Calvià). Opuestamente, se sitúan los municipios con baja población y / o de pequeña extensión de la sierra de Tramuntana y del llano central como Escorca, Estellencs, Banyalbufar, Deià, Búger, Fornalutx, Puigpunyent, Lloret, Ariany y Costitx (Figura 2).

La valoración cambia considerablemente en cuando se pasa a analizar el número de cazadores en relación a la población total. Se obtiene que, para el conjunto de la isla, hay 2,11 cazadores por cada 100 habitantes, o lo que es lo mismo, hay 1 cazador por cada 47 habitantes. Los índices más elevados se localizan en municipios de la Sierra y del interior como Mancor, Ariany, Alaró, Selva, Porreres, Costitx, Valldemossa, Algaida o Lloret, mientras que las demarcaciones con menor afición cinegética en el conjunto de la sociedad se encuentran en la conurbación constituida por Palma-Calvià-Marratxí y en municipios costeros con alta actividad turística como Andratx o Alcúdia, y en algún municipio de la Sierra como es el caso de Fornalutx (Figura 3). 
Tabla 3. Relación por municipios de titulares de licencia de caza, porcentaje sobre el total de licencias de la isla, población total y porcentaje de titulares de licencia de caza sobre la población municipal

\begin{tabular}{|c|c|c|c|c|}
\hline Municipio & $\begin{array}{c}\text { Titulares de licencia } \\
\text { de caza } 2013\end{array}$ & $\begin{array}{c}\text { \% sobre el total de titulares } \\
\text { de licencia de caza }\end{array}$ & Población 2013 & $\begin{array}{c}\text { \% de titulares sobre } \\
\text { población total }\end{array}$ \\
\hline Alaró & 367 & 2,01 & 5.217 & 7,03 \\
\hline Alcúdia & 299 & 1,64 & 20.163 & 1,48 \\
\hline Algaida & 326 & 1,79 & 5.382 & 6,06 \\
\hline Andratx & 153 & 0,84 & 10.748 & 1,42 \\
\hline Ariany & 66 & 0,36 & 914 & 7,22 \\
\hline Artà & 248 & 1,36 & 7.415 & 3,34 \\
\hline Banyalbufar & 16 & 0,09 & 583 & 2,74 \\
\hline Binissalem & 164 & 0,90 & 7.792 & 2,10 \\
\hline Búger & 40 & 0,22 & 1.029 & 3,89 \\
\hline Bunyola & 261 & 1,43 & 6.619 & 3,94 \\
\hline Calvià & 518 & 2,84 & 52.272 & 0,99 \\
\hline Campanet & 153 & 0,84 & 2.581 & 5,93 \\
\hline Campos & 497 & 2,73 & 10.144 & 4,90 \\
\hline Capdepera & 174 & 0,95 & 11.247 & 1,55 \\
\hline Consell & 108 & 0,59 & 3.834 & 2,82 \\
\hline Costitx & 74 & 0,41 & 1.192 & 6,21 \\
\hline Deià & 33 & 0,18 & 756 & 4,37 \\
\hline Escorca & 15 & 0,08 & 252 & 5,95 \\
\hline Esporles & 200 & 1,10 & 4.991 & 4,01 \\
\hline Estellencs & 16 & 0,09 & 369 & 4,34 \\
\hline Felanitx & 751 & 4,12 & 17.359 & 4,33 \\
\hline Fornalutx & 9 & 0,05 & 692 & 1,30 \\
\hline Inca & 631 & 3,46 & 31.032 & 2,03 \\
\hline Lloret & 75 & 0,41 & 1.251 & 6,00 \\
\hline Lloseta & 290 & 1,59 & 5.680 & 5,11 \\
\hline Llubí & 101 & 0,55 & 2.324 & 4,35 \\
\hline Llucmajor & 1.075 & 5,89 & 37.257 & 2,89 \\
\hline Manacor & 889 & 4,87 & 41.049 & 2,17 \\
\hline Mancor & 151 & 0,83 & 1.321 & 11,43 \\
\hline Maria & 124 & 0,68 & 2.140 & 5,79 \\
\hline Marratxí & 593 & 3,25 & 35.258 & 1,68 \\
\hline Montuïri & 170 & 0,93 & 2.838 & 5,99 \\
\hline Muro & 230 & 1,26 & 6.977 & 3,30 \\
\hline Palma & 4.409 & 24,18 & 398.162 & 1,11 \\
\hline Petra & 167 & 0,92 & 2.806 & 5,95 \\
\hline Pollença & 456 & 2,50 & 16.200 & 2,81 \\
\hline Porreres & 349 & 1,91 & 5.496 & 6,35 \\
\hline Puigpunyent & 57 & 0,31 & 2.010 & 2,84 \\
\hline Sa Pobla & 286 & 1,57 & 12.901 & 2,22 \\
\hline Sant Joan & 89 & 0,49 & 1.973 & 4,51 \\
\hline Sant Llorenç & 158 & 0,87 & 7.857 & 2,01 \\
\hline Santa Eugènia & 90 & 0,49 & 1.723 & 5,22 \\
\hline Santa Margalida & 307 & 1,68 & 12.243 & 2,51 \\
\hline Santa Maria & 287 & 1,57 & 6.500 & 4,42 \\
\hline Santanyí & 444 & 2,43 & 11.784 & 3,77 \\
\hline Selva & 262 & 1,44 & 3.869 & 6,77 \\
\hline Sencelles & 112 & 0,61 & 3.234 & 3,46 \\
\hline Ses Salines & 182 & 1,00 & 5.273 & 3,45 \\
\hline Sineu & 163 & 0,89 & 3.715 & 4,39 \\
\hline Sóller & 763 & 4,18 & 14.229 & 5,36 \\
\hline Son Servera & 229 & 1,26 & 11.146 & 2,05 \\
\hline Valldemossa & 124 & 0,68 & 2.042 & 6,07 \\
\hline Vilafranca & 146 & 0,80 & 2.922 & 5,00 \\
\hline Otros & 217 & 1,19 & 0 & 0,00 \\
\hline Indet. & 122 & 0,67 & 0 & 0,00 \\
\hline TOTAL & 18.236 & 100,00 & 864.763 & 2,11 \\
\hline
\end{tabular}

Fuente: Servicio de Caza del Departament de Desenvolupament Local del Consell de Mallorca (2013) e IBESTAT (2013). Elaboración propia 
Figura 2. Distribución municipal de los titulares de licencia de caza

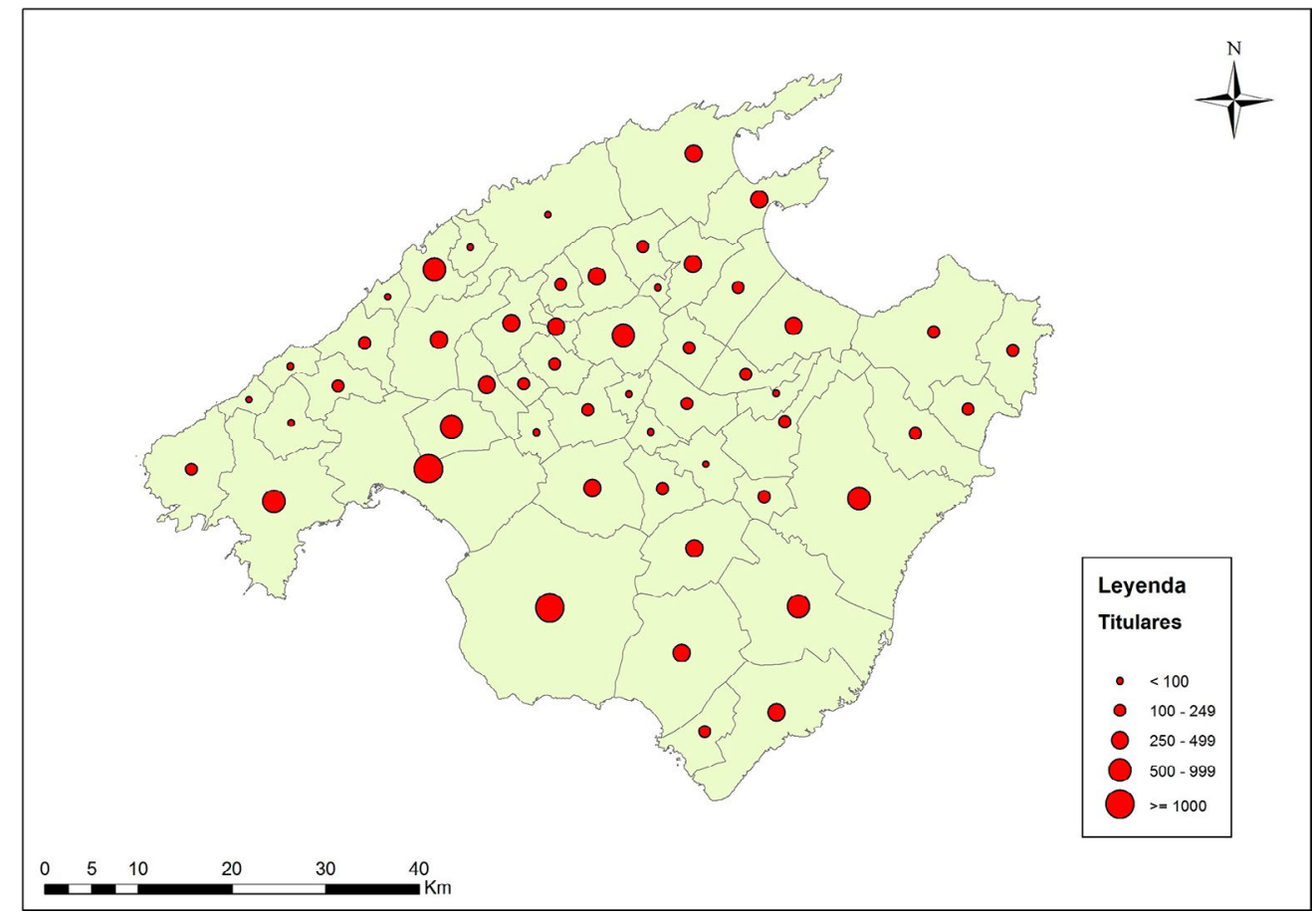

Elaboración propia

Figura 3. Densidad de titulares de licencia de caza en relación a la población total

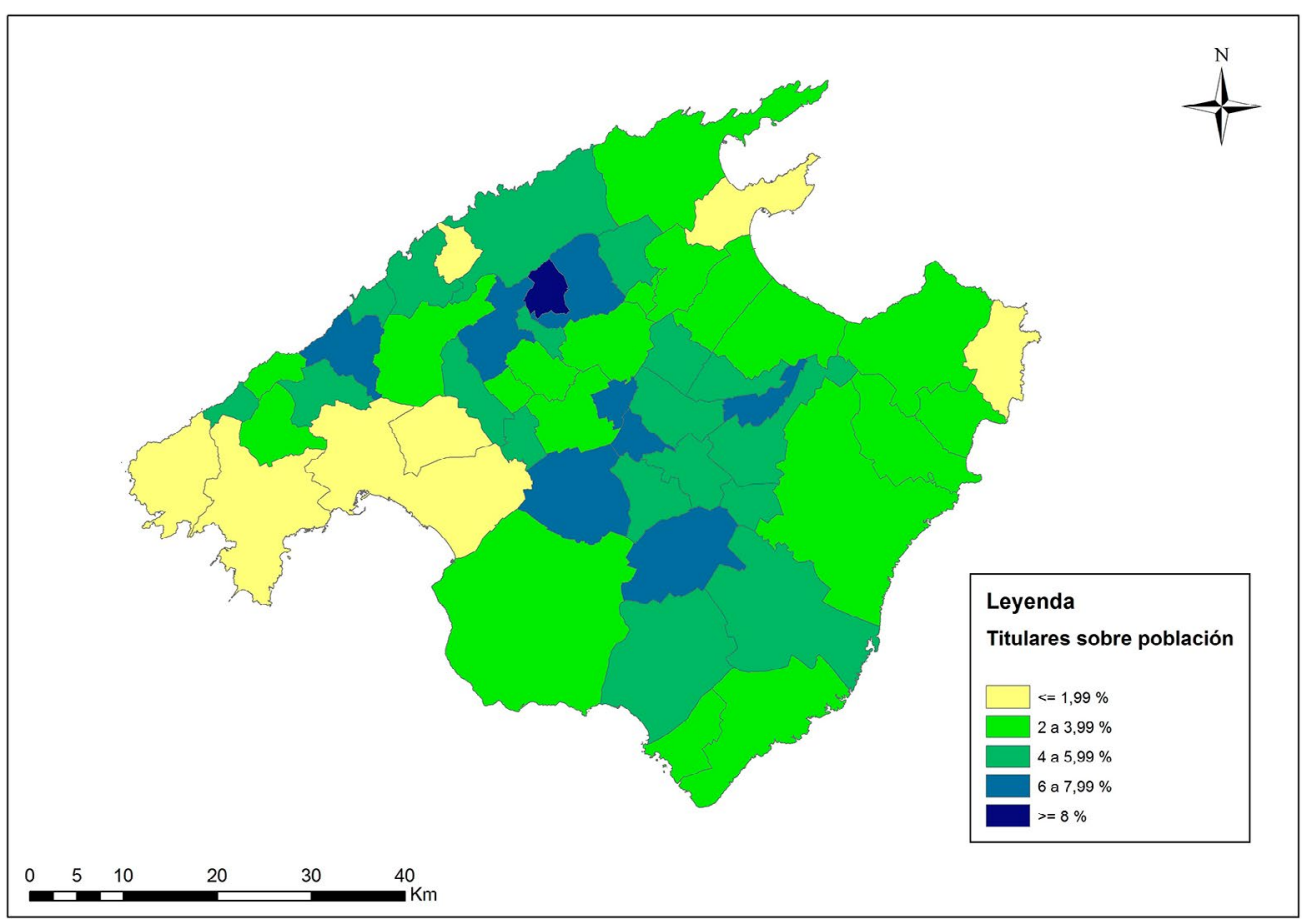

Elaboración propia

\subsubsection{Edad de las personas titulares de licencia de caza}

La distribución por edades del colectivo de cinegético refleja un notable envejecimiento y evidencia la falta de relevo generacional. Los grupos de más de 50 años son claramente más numerosos que los que no 
alcanzan esta edad. Incluso los cazadores que tienen más de 81 años son más numerosos que los menores de 21 años. La edad media de los titulares de licencia de caza en Mallorca es de 53,5 años.

De los 18.236 titulares con licencia de caza en vigor en Mallorca, el 2,12\% tiene menos de 21 años, el $19,36 \%$ tiene entre 21 y 40 años, el 41,72\% tiene una edad entre los 41 y los 60 años, el 33,97\% tiene una edad entre 61 y 80 años, y un 2,66\% tiene más de 81 años. No se ha podido obtener la edad de un $0,17 \%$ de titulares (Tabla 4).

Tabla 4. Grupos de edad de las personas titulares de licencia de caza en Mallorca, 2013

\begin{tabular}{|c|c|c|}
\hline Grupo de edad (años) & Titulares & Porcentaje \\
\hline$<21$ & 386 & 2,12 \\
\hline $21-30$ & 1.135 & 6,22 \\
\hline $31-40$ & 2.396 & 13,14 \\
\hline $41-50$ & 3.676 & 20,16 \\
\hline $51-60$ & 3.932 & 21,56 \\
\hline $61-70$ & 4.071 & 22,32 \\
\hline $71-80$ & 2.124 & 11,65 \\
\hline$>81$ & 485 & 2,66 \\
\hline Indet. & 31 & 0,17 \\
\hline Total & 18.236 & 100,00 \\
\hline
\end{tabular}

Fuente: Servicio de Caza del Departament de Desenvolupament Local del Consell de Mallorca (2013). Elaboración propia

\subsubsection{Género de las personas titulares de licencia de caza}

La caza en Mallorca es practicada mayoritariamente por hombres, la presencia femenina es estadísticamente ínfima. Del total de los 18.236 titulares de licencias de caza en Mallorca únicamente 293 son mujeres $(1,61 \%)$ (Tabla 5). En cuanto al género femenino, los municipios con mayor número absoluto de licencias son Palma (81), Manacor y Llucmayor (con 20), Marratxí (13) y Sóller e Inca (12). Diez municipios no disponen de ninguna licencia de caza femenina. Comparando el número de licencias femeninas en relación con la población municipal mayor de 15 años, se obtiene que los mayores porcentajes se obtienen en municipios de montaña atendiendo sobre todo a razones históricas de participación de la mujer en la modalidad ancestral de zorzales a coll, tradición que a día de hoy aún perdura (Barceló Adrover y Seguí Campaner, 2017).

Tabla 5. Distribución por géneros de las personas titulares de licencia de caza en Mallorca, 2013

\begin{tabular}{|c|c|c|}
\hline Género & Titulares & Porcentaje \\
\hline Masculino & 17.604 & 96,53 \\
\hline Femenino & 293 & 1,61 \\
\hline Indet. & 339 & 1,86 \\
\hline Total & $\mathbf{1 8 . 2 3 6}$ & $\mathbf{1 0 0 , 0 0}$ \\
\hline
\end{tabular}

Fuente: Servicio de Caza del Departament de Desenvolupament Local del Consell de Mallorca (2013). Elaboración propia

\subsubsection{Tipologías de licencias de caza y recargos}

La licencia de caza de las Islas Baleares es el documento personal e intransferible cuya tenencia es necesaria para practicar la caza en el ámbito territorial de esta comunidad autónoma. Existen diferentes tipologías de licencia según la modalidad de caza a practicar o la nacionalidad de la persona cazadora (Tabla 6). En 2013 se expidieron 21.323 licencias de caza en Mallorca. Abundan sobremanera, constituyendo más de las tres cuartas partes del total, las licencias genéricas Al que habilitan para la caza menor, tanto con arma como sin arma. No obstante, cabe considerar que un $7,36 \%$ de practicantes de la caza en Mallorca se decanta por modalidades que no utilizan arma de fuego (caza de tords a coll y con podencos ibicencos, principalmente según informaciones del Servicio de Caza del Departament de Desenvolupa- 
ment Local del Consell de Mallorca). Y, en referencia a licencias por modalidades particulares, destaca la caza de perdiz con reclamo que reúne a más del $10 \%$ del total de licencias expedidas.

Tabla 6. Distribución de las tipologías de licencias de caza expedidas en Mallorca, 2013

\begin{tabular}{|l|l|l|l|}
\hline Licencia & Habilitación & Número & $\%$ \\
\hline A1 & Caza con arma y sin arma, para mayores de 18 años & 16.627 & 77,98 \\
\hline A2 & Caza con arma y sin arma, para menores de 14 a 18 años & 133 & 0,62 \\
\hline B1 & Caza sin arma de fuego, para mayores de 18 años & 1.569 & 7,36 \\
\hline B2 & Caza sin arma de fuego, para menores de 18 años & 70 & 0,33 \\
\hline C1 & Cetrería & 112 & 0,53 \\
\hline C2 & Perdiz con reclamo & 2.444 & 11,46 \\
\hline C3 & Hurón & 269 & 1,26 \\
\hline A3 & Licencia temporal de un mes para caza menor (no comunitarios) & 62 & 0,29 \\
\hline C5 & Licencia de un mes para trofeo de caza homologable & 37 & 0,17 \\
\hline Total & & 21.323 & 100 \\
\hline
\end{tabular}

Nota: Las licencias C siempre tienen que ir acompañadas de una del tipo A o B

Fuente: Servicio de Caza del Departament de Desenvolupament Local del Consell de Mallorca. Elaboración propia

Los recargos de caza mayor van asociados a las licencias de caza A1, A2, B1, B2 y A3, y habilitan a la persona interesada para la práctica de la caza mayor. En el 2013, prácticamente una de cada siete licencias susceptibles de disponer recargo, dispone de la habilitación para la práctica de la caza mayor (Tabla 7). La caza de cabras es la única actividad de caza mayor que se practica en la isla y se ha popularizado de una forma relativamente reciente en Mallorca. Hoy por hoy, la caza mayor despierta un gran interés tanto en el cazador local como en el turista cinegético debido, entre otros factores, a la recuperación de la cabra salvaje mallorquina o Balearean boc, a la homologación de trofeos por parte de organismos internacionales (Safari Club International y Conseil International de la Chasse), al diseño de estrategias de gestión en los cotos (Certificado de Calidad de Caza Mayor), a los avances normativos específicos, a la diversidad de modalidades asociadas (rifle, arco y perros y lazo) y a su contribución en la conservación y sostenibilidad de los espacios de montaña (Seguí Campaner, et al., 2014; Barceló Adrover, Seguí Campaner y Rengifo Gallego, 2017).

Tabla 7. Recargos de caza mayor expedidos en Mallorca, 2013

\begin{tabular}{|l|l|l|l|}
\hline Recargos & Habilitación & Número & \% sobre licencias con $\mathbf{R}$ \\
\hline $\mathrm{R}$ & Recargos para la práctica de la caza mayor & 2.573 & 13,93 \\
\hline
\end{tabular}

Fuente: Servicio de Caza del Departament de Desenvolupament Local del Consell de Mallorca. Elaboración propia

Como apunte complementario cabe indicar que en 2014 los ingresos obtenidos por el Consell de Mallorca mediante las licencias de caza fueron 435.417,87 € (se expidieron un total de 11.420 licencias, aunque había más en vigor debido a que se pueden tramitar por uno, dos o tres años) y los ingresos derivados de las matrículas de cotos de caza fueron 372.231 ,48 €. Por otra parte, se otorgaron 133.369,29 € a las sociedades de cazadores en concepto de subvenciones para el desarrollo de actividades sociales y ambientales.

\subsubsection{Origen de los titulares de licencia de caza}

La gran mayoría de los titulares de licencia de caza $(96,41 \%)$ residen en la comunidad autónoma de las Islas Baleares y el resto se distribuye entre otras regiones españolas $(0,53 \%)$, extranjeros $(2,62 \%$, de los cuales un $2,26 \%$ son de la Comunidad Europea y un $0,36 \%$ son extracomunitarios) habiendo un pequeño porcentaje de indeterminados por falta de datos $(0,44 \%)$. Cabe destacar la importancia de cazadores internacionales, con cifras que quintuplican los procedentes de otras comunidades españolas, hecho que pone de relieve la importancia del turismo cinegético en la isla (Barceló Adrover, Seguí Campaner y Rengifo Gallego, 2017) (Tabla 8). 
Tabla 8. Origen de las personas titulares de licencia de caza en Mallorca, 2013

\begin{tabular}{|l|l|l|}
\hline Origen & Número & \% \\
\hline CAIB & 17.581 & 96,41 \\
\hline Otras comunidades & 96 & 0,53 \\
\hline Comunidad Europea & 413 & 2,26 \\
\hline No Comunitarios & 65 & 0,36 \\
\hline Indeterminado & 81 & 0,44 \\
\hline Total & $\mathbf{1 8 . 2 3 6}$ & $\mathbf{1 0 0 , 0 0}$ \\
\hline
\end{tabular}

Fuente: Servicio de Caza del Departament de Desenvolupament Local del Consell de Mallorca. Elaboración propia

\subsection{Aspectos territoriales}

El ámbito territorial de la caza se refiere a los terrenos cinegéticos y no cinegéticos definidos por la Ley 6/2006 de 12 de abril, balear de caza y pesca fluvial. Según la misma se consideran como espacios cinegéticos los cotos, las zonas de caza controlada y los terrenos gestionados de aprovechamiento común, popularmente conocidos como terrenos libres. Los refugios de fauna son terrenos excluidos de la práctica venatoria.

\subsubsection{Los cotos de caza}

En fecha de 1 de enero de 2013, la isla de Mallorca (se excluyen las islas adyacentes como sa Dragonera y el subarchipiélago de Cabrera) dispone de 280.276,11 ha vedadas, es decir, el 77,44\% del territorio mallorquín se encuentra acotado. Las diferentes categorías administrativas son los cotos de sociedades locales, los cotos particulares, los cotos sociales, los cotos intensivos y los cotos públicos.

Por número y extensión dominan los cotos particulares, mientras que las sociedades de cazadores destacan por la gran cantidad de hectáreas gestionadas, superando 1/3 de la superficie acotada. Las 59 sociedades locales distribuidas en prácticamente todos los municipios gestionan 78 cotos, la mayoría de caza menor, y cuentan con más de 7.500 personas practicantes de la caza afiliadas (Barceló Adrover, Grimalt Gelabert y Binimelis Sebastián, 2015). Los cotos intensivos tienen escasa representatividad y son inexistentes los cotos públicos y sociales (Tabla 9).

Figura 4. Espacio acotado en Mallorca, 2013

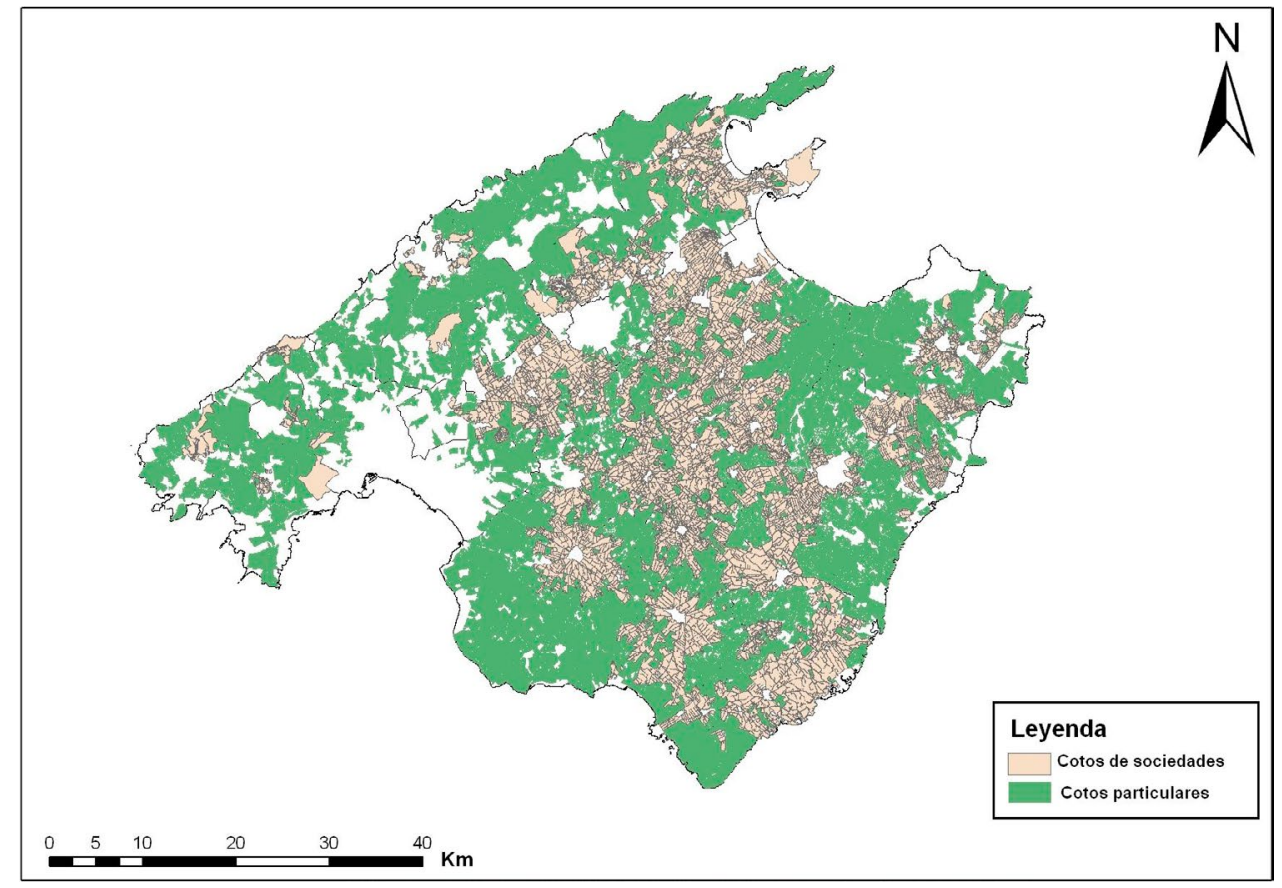

Fuente: Servicio de Caza del Departament de Desenvolupament Local del Consell de Mallorca. Elaboración propia 
Tabla 9. Tipologías de cotos, 2013

\begin{tabular}{|c|c|c|c|c|c|}
\hline & Cotos de sociedades locales & Cotos particulares & Cotos sociales & Cotos intensivos & Cotos públicos \\
\hline Número & 78 & 1.388 & 0 & 5 & 0 \\
\hline Superficie $(\mathrm{Ha})$ & $100.836,03$ & $179.440,08$ & 0 & $1.005,21$ & 0 \\
\hline
\end{tabular}

Nota: los cotos intensivos son al mismo tiempo cotos particulares

Fuente: Servicio de Caza del Departament de Desenvolupament Local del Consell de Mallorca. Elaboración propia

La superficie vedada en Mallorca se distribuye entre 1.466 cotos que suma un total de 280.276,11 ha vedadas (Tabla 10). El municipio con mayor número de cotos es Llucmajor con 259 y el que menos tiene es Búger con 2. La media es de 27,66 cotos por término municipal. La mayoría de términos tienen más del $80 \%$ del territorio vedado, siendo el tapiz acotado más denso en el centro y sur de la isla.

Tabla 10. Municipios de Mallorca con su superficie, superficie acotada, número de cotos, porcentaje del municipio acotado y superficies medias de los cotos de caza, 2013

\begin{tabular}{|c|c|c|c|c|c|}
\hline Municipio & $\begin{array}{l}\text { Superficie } \\
\text { total (ha) }\end{array}$ & $\begin{array}{l}\text { Superficie acotada } \\
\text { (ha) }\end{array}$ & $\begin{array}{l}\text { Número de } \\
\text { cotos }\end{array}$ & $\begin{array}{c}\text { \% del municipio } \\
\text { acotado }\end{array}$ & $\begin{array}{l}\text { Superficie media de } \\
\text { los cotos (ha) }\end{array}$ \\
\hline Alaró & 4.572 & $3.138,65$ & 36 & 68,65 & 87,18 \\
\hline Alcudia & 6.042 & $4.380,46$ & 11 & 72,50 & 398,22 \\
\hline Algaida & 8.970 & $7.184,73$ & 58 & 80,10 & 123,87 \\
\hline Andratx & 7.805 & $5.110,33$ & 17 & 65,48 & 300,61 \\
\hline Ariany & 2.321 & $2.209,83$ & 9 & 95,21 & 245,54 \\
\hline Artà & 13.971 & $9.439,82$ & 44 & 67,57 & 214,54 \\
\hline Banyalbufar & 1.793 & $1.179,71$ & 4 & 65,80 & 294,93 \\
\hline Binissalem & 2.979 & $2.810,61$ & 5 & 94,35 & 562,12 \\
\hline Búger & 836 & 609,74 & 2 & 72,94 & 304,87 \\
\hline Bunyola & 8.494 & $6.515,82$ & 38 & 76,71 & 171,47 \\
\hline Calvià & 14.534 & $10.360,22$ & 46 & 71,28 & 225,22 \\
\hline Campanet & 3.519 & $2.993,64$ & 19 & 85,07 & 157,56 \\
\hline Campos & 14.931 & $13.914,66$ & 90 & 93,19 & 154,61 \\
\hline Capdepera & 5.513 & $3.613,09$ & 9 & 65,54 & 401,45 \\
\hline Consell & 1.368 & 939,00 & 3 & 68,64 & 313,00 \\
\hline Costitx & 1.551 & $1.399,99$ & 11 & 90,26 & 127,27 \\
\hline Deià & 1.528 & 669,62 & 5 & 43,82 & 133,92 \\
\hline Escorca & 14.007 & $9.227,17$ & 32 & 65,88 & 288,35 \\
\hline Esporles & 3.550 & $1.766,83$ & 14 & 49,77 & 126,20 \\
\hline Estellencs & 1.341 & 599,98 & 6 & 44,74 & 100,00 \\
\hline Felanitx & 16.972 & $15.258,68$ & 65 & 89,91 & 234,75 \\
\hline Fornalutx & 1.933 & $1.497,62$ & 7 & 77,48 & 213,95 \\
\hline Inca & 5.812 & $2.524,62$ & 23 & 43,44 & 109,77 \\
\hline Lloret de vistalegre & 1.743 & $1.684,62$ & 13 & 96,65 & 129,59 \\
\hline Lloseta & 1.317 & 588,29 & 3 & 44,67 & 196,10 \\
\hline Llubí & 3.484 & $3.347,38$ & 13 & 96,08 & 257,49 \\
\hline Llucmajor & 32.683 & $29.982,46$ & 259 & 91,74 & 115,76 \\
\hline Manacor & 25.980 & $21.185,16$ & 115 & 81,54 & 184,22 \\
\hline Mancor & 2.007 & $1.663,59$ & 10 & 82,89 & 166,36 \\
\hline Maria de la Salut & 3.079 & $2.919,36$ & 17 & 94,82 & 171,73 \\
\hline Marratxí & 5.428 & $2.318,30$ & 15 & 42,71 & 154,55 \\
\hline Montuïri & 4.100 & $3.907,81$ & 13 & 95,31 & 300,60 \\
\hline Muro & 5.866 & $3.541,93$ & 8 & 60,38 & 442,74 \\
\hline Palma & 19.518 & $5.535,16$ & 45 & 28,36 & 123,00 \\
\hline Petra & 7.033 & $6.546,07$ & 22 & 93,08 & 297,55 \\
\hline Pollença & 14.962 & $13.705,66$ & 48 & 91,60 & 285,53 \\
\hline Porreres & 8.699 & $8.247,55$ & 41 & 94,81 & 201,16 \\
\hline Puigpunyent & 4.171 & $2.704,01$ & 17 & 64,83 & 159,06 \\
\hline Sa Pobla & 4.788 & $3.476,64$ & 11 & 72,61 & 316,06 \\
\hline Sant Joan & 3.844 & $3.637,09$ & 6 & 94,62 & 606,18 \\
\hline Sant Llorenç & 8.165 & $6.912,88$ & 34 & 84,66 & 203,32 \\
\hline
\end{tabular}




\begin{tabular}{|c|c|c|c|c|c|}
\hline Santa Eugènia & 2.023 & $1.735,63$ & 9 & 85,79 & 192,85 \\
\hline Santa Margalida & 8.647 & $7.872,86$ & 37 & 91,05 & 212,78 \\
\hline Santa Maria del Camí & 3.740 & $3.029,15$ & 9 & 80,99 & 336,57 \\
\hline Santanyí & 12.432 & $11.359,84$ & 18 & 91,38 & 631,10 \\
\hline Selva & 4.801 & $3.902,11$ & 15 & 81,28 & 260,14 \\
\hline Sencelles & 5.280 & $4.660,35$ & 37 & 88,26 & 125,96 \\
\hline Ses Salines & 3.875 & $3.573,95$ & 8 & 92,23 & 146,74 \\
\hline Sineu & 4.759 & $4.502,65$ & 26 & 94,61 & 173,18 \\
\hline Sóller & 4.218 & $1.906,86$ & 14 & 45,21 & 136,20 \\
\hline Son Servera & 4.275 & $3.273,87$ & 16 & 76,58 & \\
\hline Valldemossa & 4.303 & $2.909,21$ & 21 & 67,61 & 13,62 \\
\hline Vilafranca de Bonany & 2.386 & $2.300,85$ & 12 & 96,43 & 191,74 \\
\hline Total Mallorca & 361.948 & $280.276,11$ & 1.466 & 77,44 & 191,18 \\
\hline
\end{tabular}

Fuente: Servicio de Caza del Departament de Desenvolupament Local del Consell de Mallorca. Elaboración propia

\subsubsection{Total de espacios cinegéticos, refugios de fauna y núcleos urbanos: La definición del mapa cinegético de Mallorca}

La actividad cinegética asume una gran importancia territorial en Mallorca. Si a las cifras de espacios acotados se añaden las 6 zonas de caza controlada con una superficie de 1.670,58 ha (0,46\% del territorio insular) y los terrenos libres que alcanzan una superficie de 51.072,08 ha (14,11\% del territorio insular) el resultado es que 333.018,83 ha (92,01\%) son susceptibles de aprovechamiento cinegético en Mallorca (Tabla 11).

Las zonas de caza controlada son espacios cinegéticos gestionados por la Administración situados mayoritariamente en zonas de montaña y en los que las actividades cinegéticas se limitan en gran medida al control poblacional de cabras.

Los terrenos popularmente denominados libres son espacios no constituidos cotos ni sometidos a refugios de fauna ni a otras figuras de protección, susceptibles de aprovechamiento cinegético siempre que dispongan de un plan técnico o que el municipio donde se encuentran haya acogido al plan marco que elabora anualmente la administración competente en caza. Por tanto, en virtud de la Ley 6/2006 de 12 de abril, balear de caza y pesca fluvial, los terrenos libres pueden ser terrenos cinegéticos, denominados terrenos gestionados de aprovechamiento común (Art. 19), siempre y cuando dispongan de plan técnico propio o se adhieran al plan marco que publica anualmente el Consell de Mallorca, o pueden ser terrenos no cinegéticos, denominados zonas inhábiles de caza (Art.24), mientras se mantenga la falta de planificación técnica. Estos espacios aparecen concentrados alrededor de los principales núcleos de población, Palma, Inca y Manacor y en sus áreas de influencia transformadas por infraestructuras y actividades incompatibles con la caza, en el litoral urbanizado, en espacios montañosos y de difícil acceso y allí donde hay predominio de la propiedad pública. Es decir, afloran en entornos con aptitudes cinegéticas modestas, con limitaciones prácticas asociadas a fenómenos urbanos o dificultades físicas. Por otra parte, cabe considerar que los municipios con menor porcentaje de terrenos libres son aquellos donde están las sociedades de cazadores más potentes en términos sociales y territoriales (Santanyí, Llucmajor, Campos, Porreres, Santa Margalida, Pollença, ...). Entre las temporadas de caza 2011-2012 y la 2017-2018 se observa una importante reducción de los ayuntamientos que autorizan la caza en los terrenos libres, pasando de 41 municipios acogidos al plan marco en la temporada 2011-2012 a 25 en la actualidad. La presencia de cazadores foráneos en los terrenos libres, la existencia de conflictos entre cazadores y propietarios, las modalidades practicadas o la intensidad del impacto acústico de la caza a puesto fijo parece que son los principales factores que condicionan las decisiones consistoriales de habilitar o no la caza en los terrenos de régimen cinegético común. Un aspecto novedoso de la temporada 2017-2018 es la adhesión al plan marco del municipio de Artá, aunque limitando la práctica cinegética sólo a modalidades tradicionales o sin arma de fuego. En Palma, la decisión de no habilitar la caza en los terrenos libres ha sido motivo de manifestaciones y reivindicaciones de los cazadores afectados, sobre todo aquellos que no disponen de un coto privado, no pertenecen a ninguna sociedad de cazadores o no tienen recursos. Según datos publicados (Barceló Adrover, Binimelis Sebastián y Grimalt Gelabert, 2016) un 22,28\% de los cazadores caza habitualmente en terrenos libres. La progresiva inhabilitación cinegética de estos espacios puede suponer altas concentraciones en los libres dónde sí se puede cazar o el abandono de la práctica por falta de espacio, entre otros aspectos. 
Tabla 11. Superficie municipal, superficie de los espacios cinegéticos (cotos y zonas de caza controlada), superficie de los núcleos urbanos y espacios edificados, superficie de los refugios de fauna, superficie de los terrenos libres y porcentaje municipal libre, 2013

\begin{tabular}{|c|c|c|c|c|c|c|}
\hline Municipio & $\begin{array}{l}\text { Superficie } \\
\text { Total (ha) }\end{array}$ & $\begin{array}{c}\text { Superficie } \\
\text { vedada (ha) }\end{array}$ & $\begin{array}{l}\text { Superficie de núcleos } \\
\text { urbanos (ha) }\end{array}$ & $\begin{array}{c}\text { Superficie de refugios } \\
\text { de fauna (ha) }\end{array}$ & $\begin{array}{c}\text { Superficie de } \\
\text { terrenos libres (ha) }\end{array}$ & $\begin{array}{c}\% \text { de terrenos } \\
\text { libres }\end{array}$ \\
\hline Alaró & 4.572 & $3.138,65$ & 78,65 & 50,17 & $1.304,53$ & 28,53 \\
\hline Alcudia & 6.042 & $4.380,46$ & 723,26 & 101,84 & 836,44 & 13,84 \\
\hline Algaida & 8.970 & $7.184,73$ & 118,17 & 0 & $1.667,10$ & 18,59 \\
\hline Andratx & 7.805 & $5.110,33$ & 587,22 & 81,18 & $2.026,27$ & 25,96 \\
\hline Ariany & 2.321 & $2.209,83$ & 30,18 & 0 & 80,99 & 3,49 \\
\hline Artà & 13.971 & $9.900,44$ & 231,34 & $1.652,69$ & $2.186,53$ & 15,65 \\
\hline Banyalbufar & 1.793 & $1.179,71$ & 22,1 & 439,21 & 151,98 & 8,48 \\
\hline Binissalem & 2.979 & $2.810,61$ & 135,98 & 0 & 32,41 & 1,09 \\
\hline Búger & 836 & 609,74 & 18,04 & 34,29 & 173,93 & 20,81 \\
\hline Bunyola & 8.494 & $6.515,82$ & 269,13 & 84 & $1.625,05$ & 19,13 \\
\hline Calvià & 14.534 & $10.360,22$ & $2.479,25$ & 0 & $1.694,53$ & 11,66 \\
\hline Campanet & 3.519 & $3.038,55$ & 53,67 & 55,83 & 370,95 & 10,54 \\
\hline Campos & 14.931 & $13.914,66$ & 443,4 & 18,84 & 554,10 & 3,71 \\
\hline Capdepera & 5.513 & $3.613,09$ & 580,91 & 65,04 & $1.253,96$ & 22,75 \\
\hline Consell & 1.368 & 939,00 & 73,47 & 40,41 & 315,12 & 23,04 \\
\hline Costitx & 1.551 & $1.399,99$ & 14,48 & 0 & 136,53 & 8,80 \\
\hline Deià & 1.528 & 669,62 & 50,18 & 0 & 808,20 & 52,89 \\
\hline Escorca & 14.007 & $10.087,17$ & 135,17 & $2.601,14$ & $1.183,52$ & 8,45 \\
\hline Esporles & 3.550 & $1.766,83$ & 74,01 & 0 & $1.709,16$ & 48,15 \\
\hline Estellencs & 1.341 & 851,56 & 5,28 & 0 & 484,16 & 36,10 \\
\hline Felanitx & 16.972 & $15.258,68$ & 469,56 & 3,99 & $1.239,77$ & 7,30 \\
\hline Fornalutx & 1.933 & $1.497,62$ & 9,86 & 0 & 425,52 & 22,01 \\
\hline Inca & 5.812 & $2.524,62$ & 286,75 & 16,87 & $2.983,76$ & 51,34 \\
\hline Lloret de vistalegre & 1.743 & $1.684,62$ & 13,06 & 0 & 45,32 & 2,60 \\
\hline Lloseta & 1.317 & 588,29 & 92,61 & 0 & 636,10 & 48,30 \\
\hline Llubí & 3.484 & $3.347,38$ & 62,69 & 0 & 73,93 & 2,12 \\
\hline Llucmajor & 32.683 & $30.035,99$ & 987,36 & 80,66 & $1.578,99$ & 4.83 \\
\hline Manacor & 25.980 & $21.185,16$ & $1.160,53$ & 28,57 & $3.605,74$ & 13,88 \\
\hline Mancor & 2.007 & $1.663,59$ & 29,38 & 58,36 & 255,67 & 12,74 \\
\hline Maria de la Salut & 3.079 & $2.919,36$ & 65,87 & 0 & 93,77 & 3,05 \\
\hline Marratxí & 5.428 & $2.318,30$ & $1.134,64$ & 0 & $1.975,06$ & 36,39 \\
\hline Montuïri & 4.100 & $3.907,81$ & 55,02 & 0 & 137,17 & 3,35 \\
\hline Muro & 5.866 & $3.541,93$ & 297,03 & $1.518,18$ & 508,86 & 8,67 \\
\hline Palma & 19.518 & $5.535,16$ & $5.751,3$ & 18,08 & $8.213,46$ & 42,08 \\
\hline Petra & 7.033 & $6.546,07$ & 69,73 & 16,99 & 400,21 & 5,69 \\
\hline Pollença & 14.962 & $13.705,66$ & 476,63 & 279,42 & 500,29 & 3,34 \\
\hline Porreres & 8.699 & $8.247,55$ & 122,99 & 20,24 & 308,22 & 3,54 \\
\hline Puigpunyent & 4.171 & $2.704,01$ & 101,5 & 128,93 & $1.236,56$ & 29,65 \\
\hline Sa Pobla & 4.788 & $3.476,64$ & 295,42 & 153,45 & 862,49 & 18,01 \\
\hline Sant Joan & 3.844 & $3.637,09$ & 54,34 & 0 & 152,57 & 3,97 \\
\hline Sant Llorenç & 8.165 & $6.912,88$ & 367,57 & 30,47 & 854,08 & 10,46 \\
\hline Santa Eugènia & 2.023 & $1.735,63$ & 39,13 & 0 & 248,24 & 12,27 \\
\hline Santa Margalida & 8.647 & $7.872,86$ & 402,9 & 0 & 371,24 & 4,29 \\
\hline Santa Maria del Camí & 3.740 & $3.029,15$ & 108,48 & 0 & 602,37 & 16,11 \\
\hline Santanyí & 12.432 & $11.359,84$ & 764,24 & 0 & 307,92 & 2,48 \\
\hline Selva & 4.801 & $3.902,11$ & 61,01 & 390,8 & 447,08 & 9,31 \\
\hline Sencelles & 5.280 & $4.660,35$ & 50,84 & 2,63 & 566,18 & 10,72 \\
\hline Ses Salines & 3.875 & $3.573,95$ & 166,74 & 0 & 134,31 & 3,47 \\
\hline Sineu & 4.759 & $4.502,65$ & 72,72 & 0 & 183,63 & 3,86 \\
\hline Sóller & 4.218 & $1.906,86$ & 222,7 & 0 & $2.088,44$ & 49,51 \\
\hline Son Servera & 4.275 & $3.273,87$ & 312,55 & 14,66 & 673,92 & 15,76 \\
\hline Valldemossa & 4.303 & $2.909,21$ & 89,55 & 544,43 & 759,81 & 17,66 \\
\hline Vilafranca de Bonany & 2.386 & $2.300,85$ & 79,21 & 0 & 5,94 & 0,25 \\
\hline Total Mallorca & 361.948 & $281.946,75$ & $20.397,8$ & $8.531,37$ & $51.072,08$ & 14,11 \\
\hline
\end{tabular}

Fuente: Servicio de Caza del Departament de Desenvolupament Local del Consell de Mallorca. Elaboración propia 
Los refugios de fauna son terrenos excluidos del aprovechamiento cinegético por el carácter biológico, científico o educativo, atendiendo a razones de conservación de especies. En 2013 hay en Mallorca 75 refugios de fauna, los cuales ocupan una superficie 8.531,37 ha. Los lugares de Mallorca con más superficie incluida bajo la figura de refugios de fauna son la sierra de Tramuntana junto con la Albufera de Muro-Sa Pobla y la península de Levante. La mayor parte corresponde a espacios naturales protegidos y a fincas públicas. Cerca del $80 \%$ de la superficie de los refugios es de titularidad pública.

A partir de la superposición de estas capas se obtiene el mapa de espacios cinegéticos y no cinegéticos de Mallorca. Los terrenos libres aparecen por defecto, una vez superpuestas las figuras cinegéticas, los refugios de fauna y los núcleos urbanos (Figura 5).

Figura 5. Mapa de espacios cinegéticos y no cinegéticos de Mallorca, 2013

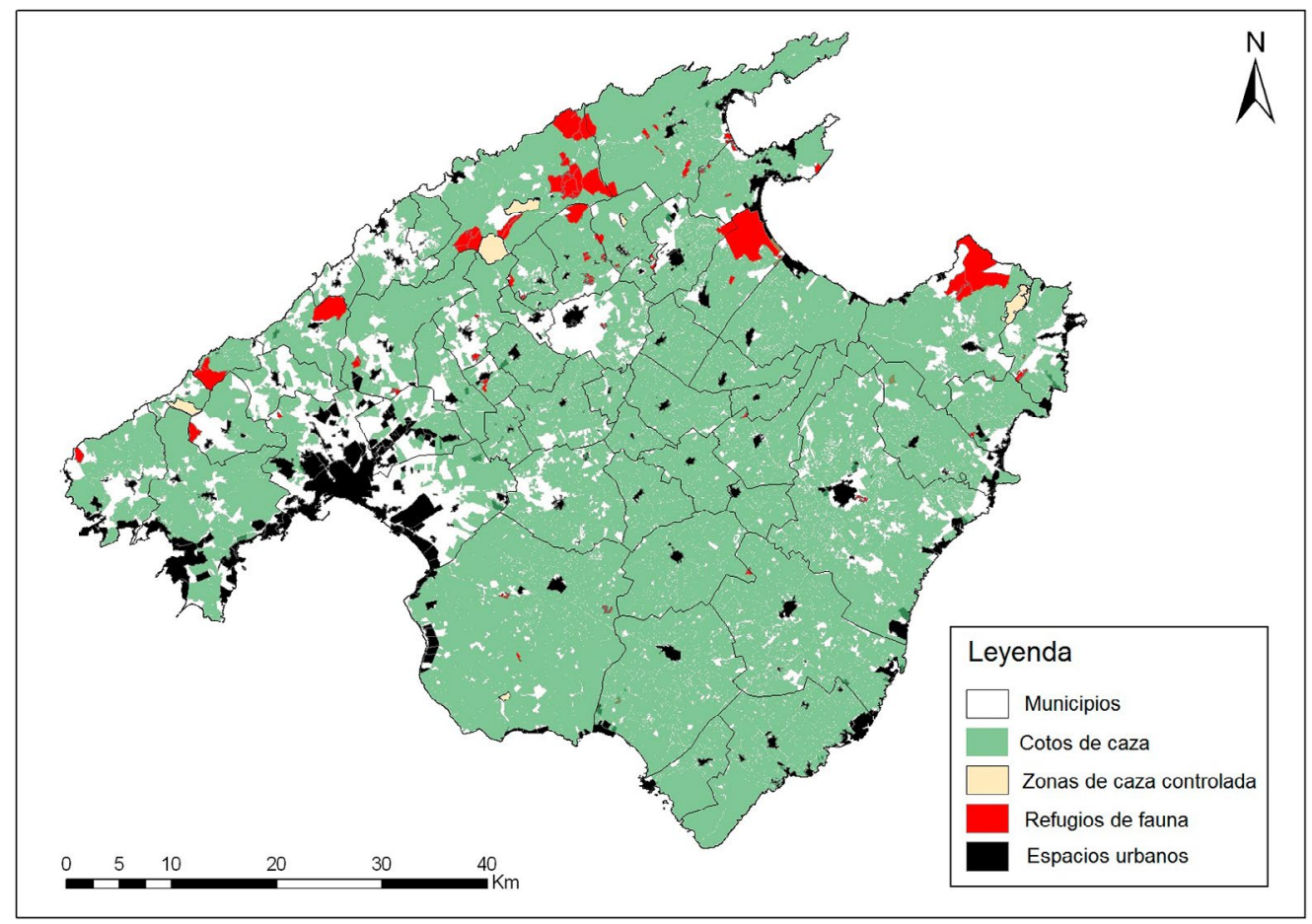

Elaboración propia

\subsection{Superficies susceptibles de aprovechamiento cinegético por titular de licencia de caza en el ámbito municipal}

La combinación del número de titulares de licencia de caza con las hectáreas susceptibles de aprovechamiento cinegético (en adelante ha SAC) permite determinar el número teórico de hectáreas de caza por cazador en cada demarcación municipal.

Se entiende como ha SAC la suma de terrenos vedados más las superficies de aprovechamiento cinegético común (terrenos libres). Sin embargo, se trata de un índice teórico atendiendo a las elevadas posibilidades de movilidad dentro de la isla. Para el conjunto de Mallorca, la media resultante de ha SAC por cazador es de 18,61 aunque hay grandes diferencias entre el municipio con más ha SAC por cazador, que es Escorca (751,38 ha SAC por cazador), y el municipio con menos ha SAC por practicante de la actividad cinegética, que es Palma (3,12 ha SAC por cazador). Un total de 17 municipios están por debajo de la media de ha SAC y 36 por encima. En cuanto a la categorización propuesta en el apartado metodológico, 4 municipios son grandes demandantes, 5 demandantes, 19 equilibrados, 20 ofertantes y 5 grandes ofertantes (Tabla 12). En su conjunto, Mallorca presenta un equilibrio en cuanto a cazadores / ha de terreno cinegético.

Las demarcaciones catalogadas como grandes demandantes y demandantes se localizan en torno a Palma y su área de influencia más próxima alineada con la autopista que comunica la capital con Inca, junto con el municipio de Sóller —única ciudad inserta en la parte central de la sierra de Tramuntana-. 
Las demarcaciones con valores equilibrados se ubican, en su mayor parte, cerca de los demandantes y grandes demandantes, en sus extremos Este y Oeste, además de en el litoral Sur y Levante de la isla. Los considerados ofertantes ocupan buena parte del centro insular, las franjas Sur y Este, y diversos enclaves alternos en la sierra de Tramuntana. Finalmente, los grandes ofertantes, se sitúan exclusivamente en la sierra de Tramuntana (Figura 6).

Tabla 12. Municipios, titulares con licencia de caza, hectáreas susceptibles de aprovechamiento cinegético (ha/SAC), ha SAC/cazador y categorización

\begin{tabular}{|c|c|c|c|c|}
\hline Municipio & Titulares & Ha SAC & Ha SAC/titulares & Categoría \\
\hline Alaró & 367 & $4.443,18$ & 12,11 & Demandante \\
\hline Alcudia & 299 & $5.216,9$ & 17,45 & Equilibrado \\
\hline Algaida & 326 & $8.851,83$ & 27,15 & Ofertante \\
\hline Andratx & 153 & $7.136,6$ & 46,64 & Ofertante \\
\hline Ariany & 66 & $2.290,82$ & 34,71 & Ofertante \\
\hline Artà & 248 & $12.086,97$ & 48,74 & Ofertante \\
\hline Banyalbufar & 16 & $1.331,69$ & 83,23 & Gran ofertante \\
\hline Binissalem & 164 & $2.843,02$ & 17,34 & Equilibrado \\
\hline Búger & 40 & 783,67 & 19,59 & Equilibrado \\
\hline Bunyola & 261 & $8.140,87$ & 31,19 & Ofertante \\
\hline Calvià & 518 & $12.054,75$ & 23,27 & Equilibrado \\
\hline Campanet & 153 & $3.409,5$ & 22,28 & Equilibrado \\
\hline Campos & 497 & $14.468,76$ & 29,11 & Ofertante \\
\hline Capdepera & 174 & $4.867,05$ & 27,97 & Ofertante \\
\hline Consell & 108 & $1.254,12$ & 11,61 & Demandante \\
\hline Costitx & 74 & $1.536,52$ & 20,76 & Equilibrado \\
\hline Deià & 33 & $1.477,82$ & 44,78 & Ofertante \\
\hline Escorca & 15 & $11.270,69$ & 751,38 & Gran ofertante \\
\hline Esporles & 200 & $3.475,99$ & 17,38 & Equilibrado \\
\hline Estellencs & 16 & $1.335,72$ & 83,48 & Gran ofertante \\
\hline Felanitx & 751 & $16.498,45$ & 21,97 & Equilibrado \\
\hline Fornalutx & 9 & $1.923,14$ & 213,68 & Gran ofertante \\
\hline Inca & 631 & $5.508,38$ & 8,73 & Demandante \\
\hline Lloret de vistalegre & 75 & $1.729,94$ & 23,07 & Equilibrado \\
\hline Lloseta & 290 & $1.224,39$ & 4,22 & Gran demandante \\
\hline Llubí & 101 & $3.421,31$ & 33,87 & Ofertante \\
\hline Llucmajor & 1.075 & $31.614,98$ & 29,41 & Ofertante \\
\hline Manacor & 889 & $24.790,9$ & 27,89 & Ofertante \\
\hline Mancor & 151 & $1.919,26$ & 12,71 & Demandante \\
\hline Maria de la Salut & 124 & $3.013,13$ & 24,30 & Equilibrado \\
\hline Marratxí & 593 & $4.293,36$ & 7,24 & Demandante \\
\hline Montuïri & 170 & $4.044,98$ & 23,79 & Equilibrado \\
\hline Muro & 230 & $4.050,79$ & 17,61 & Equilibrado \\
\hline Palma & 4.409 & $13.748,62$ & 3,12 & Gran demandante \\
\hline Petra & 167 & $6.946,28$ & 41,59 & Ofertante \\
\hline Pollença & 456 & $14.205,95$ & 31,15 & Ofertante \\
\hline Porreres & 349 & $8.555,77$ & 24,52 & Equilibrado \\
\hline Puigpunyent & 57 & $3.940,57$ & 69,13 & Gran ofertante \\
\hline Sa Pobla & 286 & $4.339,13$ & 15,17 & Equilibrado \\
\hline Sant Joan & 89 & $3.789,66$ & 42,58 & Ofertante \\
\hline Sant Llorenç & 158 & $7.766,96$ & 49,16 & Ofertante \\
\hline Santa Eugènia & 90 & $1.983,87$ & 22,04 & Equilibrado \\
\hline Santa Margalida & 307 & $8.244,1$ & 26,85 & Ofertante \\
\hline Santa Maria del Camí & 287 & $3.631,52$ & 12,65 & Demandante \\
\hline Santanyí & 444 & $11.667,76$ & 26,28 & Ofertante \\
\hline Selva & 262 & $4.349,19$ & 16,60 & Equilibrado \\
\hline Sencelles & 112 & $5.226,53$ & 46,67 & Ofertante \\
\hline Ses Salines & 182 & $3.708,26$ & 20,38 & Equilibrado \\
\hline Sineu & 163 & $4.686,28$ & 28,75 & Ofertante \\
\hline Sóller & 763 & $3.995,3$ & 5,24 & Gran demandante \\
\hline Son Servera & 229 & $3.947,79$ & 17,24 & Equilibrado \\
\hline
\end{tabular}




\begin{tabular}{|c|c|c|c|c|}
\hline Valldemossa & 124 & $3.669,02$ & 29,59 & Ofertante \\
\hline Vilafranca de Bonany & 146 & $2.306,79$ & 15,80 & Equilibrado \\
\hline TOTAL & $\mathbf{1 7 . 8 9 7}$ & $\mathbf{3 3 3 . 0 1 8 , 8 3}$ & $\mathbf{1 8 , 6 1}$ & Equilibrado \\
\hline
\end{tabular}

Fuente: Servicio de Caza del Departament de Desenvolupament Local del Consell de Mallorca. Elaboración propia

Figura 6. Categorización de los municipios mallorquines según el número de Ha SAC por titular de licencia de caza

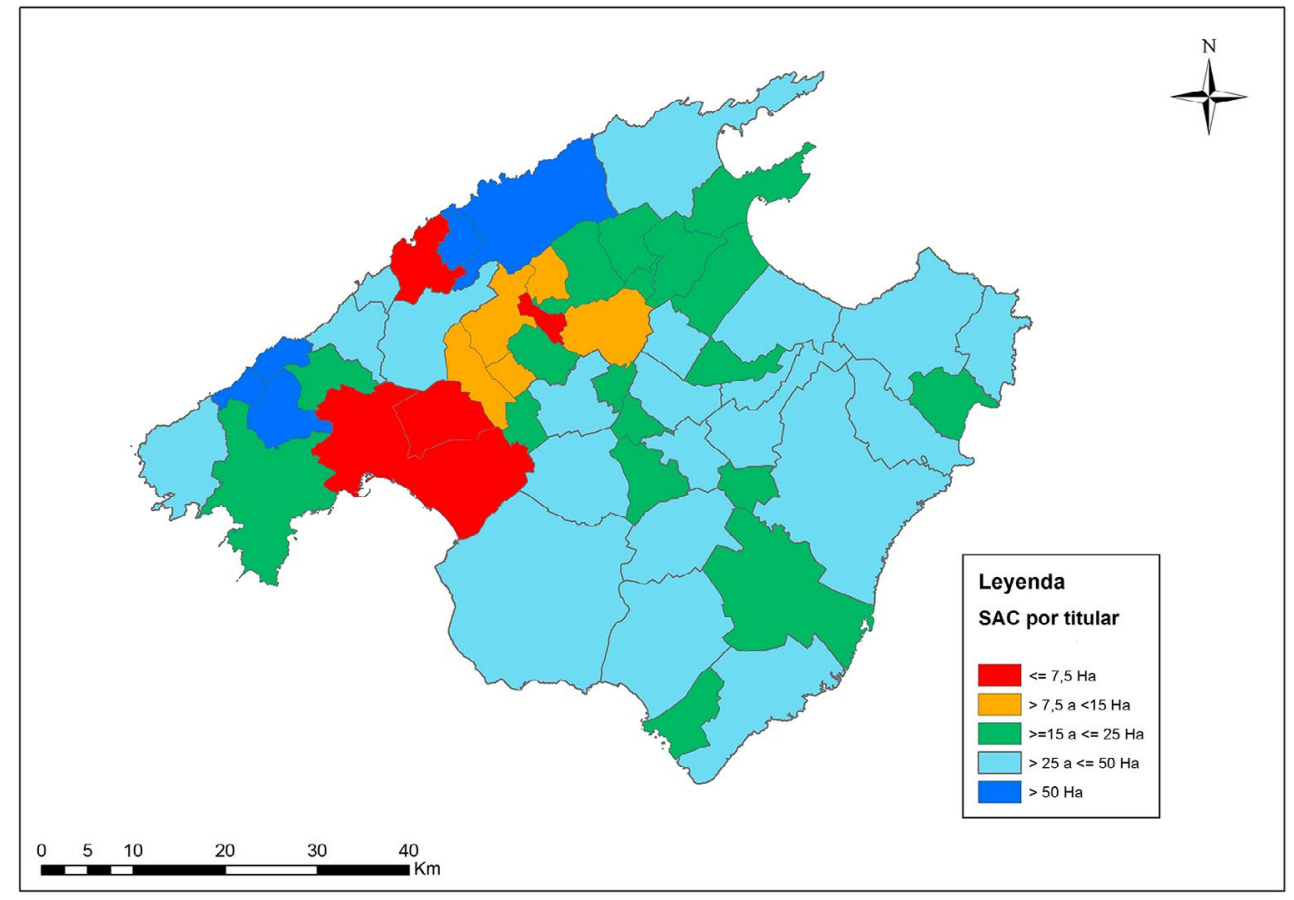

Fuente: Servicio de Caza del Departament de Desenvolupament Local del Consell de Mallorca. Elaboración propia

Figura 7. Categorización de los municipios mallorquines en demandantes, equilibrados y ofertantes

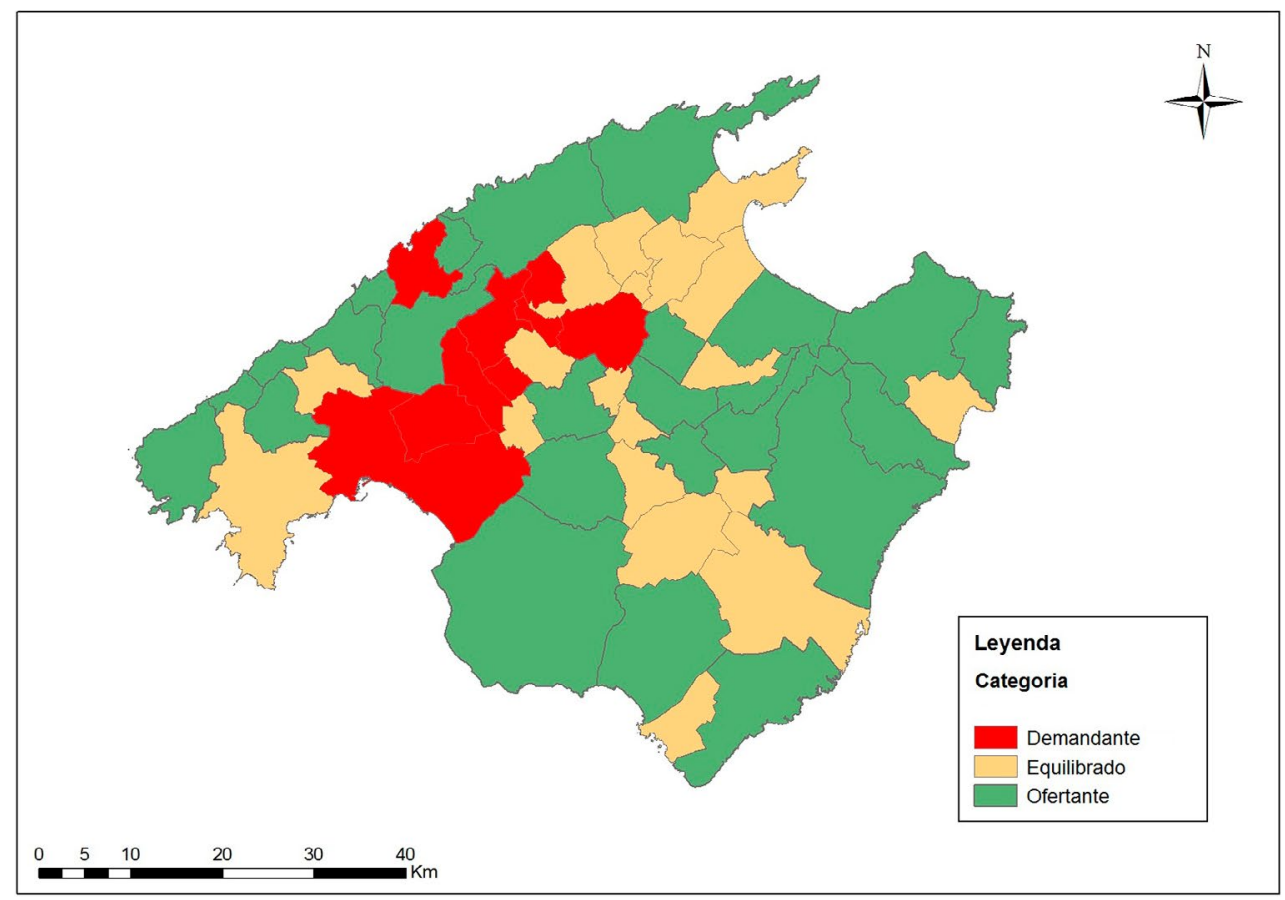

Elaboración propia 
La reagrupación de los municipios resultantes de la Tabla 12 en tan solo 3 categorías, ofertantes (incluye los ofertantes y grandes ofertantes), equilibrados y demandantes (incluye los demandes y grandes demandantes), da por resultado un nuevo mapa (Figura 7) con un patrón de distribución definido en torno a dos ejes que subdividen la isla en 4 cuadrantes. Se observa un eje sudoeste-noreste y otro de noroeste-sureste de demarcaciones municipales demandantes y equilibradas, polarizadas por un núcleo central de alta demanda de espacio cinegético que bascula hacia la capital insular, Palma, y su área de influencia más próxima y vertebrada linealmente con la autopista de Inca. A continuación de esta región demandante, aparecen líneas de municipios equilibrados. Unas demarcaciones aparecen atraídas por la conurbación de la capital, otras se presentan hacía el extremo noreste, otras definen una sección transversal desde el centro del Raiguer hacia el sureste y, finalmente, surgen algunos municipios dispersos con límites costeros. Flanqueando los espacios demandantes y equilibrados emergen los municipios ofertantes, que son mayoritarios respecto a los demás. Ocupan la parte septentrional del Pla, el Llevant, el Migjorn y la sierra de Tramuntana en su mayor parte. Se corresponde con zonas de baja y moderada presión antrópica, excepto en los límites litorales de la costa este-sur, debido a la expansión turística.

\section{Discusión}

\subsection{Un trabajo con antecedentes metodológicos y con respuestas a cuestiones históricas}

El estudio se asemeja metodológicamente a los publicados por López Ontiveros y García Verdugo (1991) y López Ontiveros (1994) en los cuales consignan para las distintas comunidades autónomas cinco indicadores que permiten diagnosticar su demanda (número de licencias de caza) y oferta (piezas de caza mayor, peso de caza, cotos privados y renta generada por la caza). Si el porcentaje de lo que se considera demanda es superior a todos los que se refieren a indicadores de oferta es claro que estamos en presencia de "demandantes netos" y en caso contrario, de "ofertantes netos". Existen, no obstante, algunos casos de más dudosa interpretación. Los resultados expuestos por los autores indicaban:

- Como claros ofertantes de caza aparecían Castilla-La Mancha y Extremadura, y como dudosos, aunque con tendencia a serlo, Aragón, Castilla y León.

- Andalucía se perfilaba nítidamente como uno de los principales productores, pero presentando cierto equilibrio entre oferta y demanda.

- Como demandantes netos aparecían Galicia, Asturias, País Vasco, La Rioja, Cataluña, Madrid, Valencia y Murcia. No tan nítidamente, pero con tendencia a serlo, lo eran Cantabria y Navarra. Baleares, en conjunto se consideraba también como claro demandante, excepto en caza menor, por la importancia de "otra caza volátil" en las que se incluyen las aves de paso. Para Canarias, se consideró imposible establecer un diagnóstico preciso.

En nuestro caso, en cuanto a la oferta, solo consideramos la variable espacios cinegéticos atendiendo a la baja oferta en caza mayor (de las 27 especies cinegéticas en Mallorca sólo 1 es de caza mayor), a la falta de calidad metodológica en las estimaciones sobre las cuales se calculan los pesos de las especies y a la ausencia de datos económicos. De hecho, el grado de investigación sobre las poblaciones de especies cinegéticas es todavía muy bajo y son pocos los estudios y la información disponible sobre la gestión de especies (Marsal i Caselles y Porta Josa, 2001). También hay muy poca información referente a la valoración económica de la caza, la actividad cinegética, y el gasto del cazador, y no hay un mercado claro y transparente que permita disponer de unos precios de referencia, ofertas de caza, entre otras limitaciones (Marsal i Caselles y Porta Josa, 2001; González et al., 2004).

Además, justificamos la utilización de los espacios cinegéticos debido a que los datos de caza mayor en Mallorca no son homogéneos en territorio (la caza mayor solo se practica en las zonas de montaña) y no se disponen de datos municipales ni del peso de las capturas ni económicos.

La metodología utilizada en este trabajo junto con la utilización de sistemas de información geográfica como herramienta de análisis y representación de, en este caso, variables cinegéticas supone abordar asuntos de gran calado planteados previamente por geógrafos pioneros en el estudio científico de la caza. Concretamente, nos referimos a los argumentos sobre el estado de la cuestión de la investigación de la caza en España planteados por López Ontiveros (1992) y de los cuales destacamos:

- El convencimiento del autor de que en lo sucesivo se incrementarían los estudios sobre caza. 
- La necesidad de disponer de un mapa de cotos de España. Hasta el momento la obra de Cecilia y Martínez Garrido (1988), constituía un logro parcial.

- El desconocimiento casi absoluto desde el punto de vista de la demanda, sobre los flujos de cazadores entre comunidades, provincias y municipios, campo y ciudad.

- La existencia de estadísticas endebles cronológicamente y en contenidos, así como en fiabilidad, por lo que concluye López Ontiveros que la geografía española de la caza está por hacer.

Así pues el método utilizado y los resultados obtenidos sobre aspectos sociales y territoriales de la caza en Mallorca para el año 2013 pretenden contribuir al estudio científico de la actividad cinegética desde la Geografía, aunque sea a nivel regional, dando respuesta a requerimientos históricos como la elaboración de mapas precisos sobre espacios acotados, utilizando ese precioso auxiliar geográfico, que es la estadística, proveniente de fuentes fiables y con la estructuración necesaria para poder realizar un análisis adecuado. Finalmente, también se realiza una primera aproximación, des del punto de vista municipal, a los flujos de movilidad de cazadores.

\subsection{Definición del modelo oferta-demanda de la actividad cinegética en Mallorca}

El modelo de oferta demanda de la caza en Mallorca se basa en cierta manera en la densidad de personas practicantes en relación a la superficie municipal susceptible de aprovechamiento cinegético.

El conglomerado de municipios demandantes comparte una manifiesta falta de espacios cinegéticos en relación al número de cazadores. Observando las Figuras 4 y 5, se intuye que las principales causas derivan de la elevada presión urbana, presencia de infraestructuras de comunicación y de servicios, notable existencia de terrenos libres (a día de hoy, la mayoría inhábiles) y escasez de terrenos gestionados por sociedades de cazadores. De forma mayoritaria esta zona coincide con las comarcas geográficas de Palma y Es Raiguer definidas en la Figura 1, además de Sóller en la sierra de Tramuntana. Se trata de territorios adosados al piedemonte de la principal alineación montañosa de la isla con una destacada evolución urbana, importante establecimiento de viviendas rururbanas, agricultura de secano, ganadería ovina y modesta densidad de espacios protegidos por figuras ambientales. Convergen aquí prácticas de caza menor, con la perdiz, la liebre y el zorzal como principales especies, y modalidades de caza mayor de cabras salvajes y asilvestradas.

Las demarcaciones equilibradas se expanden linealmente en diversas direcciones por la isla a partir de los municipios demandantes. En base a los mapas precedentes indicados, los espacios equilibrados, por norma general, disponen de un denso tejido de cotos de caza, privados y, sobretodo de sociedades de cazadores, con pocos refugios y escasos terrenos libres. La densidad poblacional es importante pero menor que en la categoría anterior, con asentamientos dispersos de mediana entidad, y con una ocupación territorial en aumento a medida que se aproxima la costa. El terreno llano u ondulado favorece las actividades agrarias de secano mientras que en las principales elevaciones, que raramente sobrepasan los $500 \mathrm{msnm}$, domina la vegetación forestal, con presencia de diferentes figuras de protección. En el extremo nordeste se localiza la principal zona húmeda de las Islas Baleares, s'Albufera. Los municipios equilibrados se caracterizan por la caza menor, excepto en sus límites con la sierra de Tramuntana dónde también se practica la caza mayor. Las principales especies aquí son el conejo, la liebre, la perdiz, la torcaz, el zorzal $y$, en las proximidades de la zona húmeda, las acuáticas.

De forma exógena a los municipios demandantes y equilibrados, se encuentran los municipios ofertantes. Se localizan en esta área los principales dominios de la caza mayor, sierra de Tramuntana y península de Artá, y posiblemente los mejores cotos de caza menor de la isla, principalmente en espacios de marinas de monte bajo (tanto en la zona de Llucmajor -Campos- Santanyí como en los entornos de Santa Margarita - Petra - Manacor). Se trata, por una parte, de cazaderos de gestión particular de caza mayor y de caza menor (sobre todo de migratorias, como el tordo y becada) junto con numerosos refugios de fauna en las montañas de Tramuntana y Artá y, por otra parte, de acotados de sociedades alternados con cotos particulares en el resto, con hábitats muy diversos debido al mosaico paisajístico de carácter agroforestal.

En cualquier caso, esta distribución sectorial periférica de los municipios ofertantes frente a un núcleo duro de municipios demandantes seguido por otros de equilibrados supone simplemente un esquema teórico de la oferta y demanda de espacio cinegético en la isla. Este modelo tiene una alta correlación con la distribución de la población, aunque también cabe considerar otros factores como los usos del suelo 
o el régimen de propiedad que se escapan del alcance de las variables analizadas. Sí que se puede afirmar que, durante la temporada de caza, existen importantes desplazamientos dentro de la isla y entre municipios con motivaciones cinegéticas. Sobre este asunto, que debería ser objeto de mayor análisis, se disponen de datos básicos obtenidos mediante una encuesta representativa al colectivo cinegético mallorquín (Barceló Adrover, Binimelis Sebastián y Grimalt Gelabert, 2016) que concluye indicando que la mayoría de las personas encuestadas se mueve entre 5 y $30 \mathrm{~km}$, y que la distancia media de desplazamientos es de $18,82 \mathrm{~km}$, que equivale a unos 20 minutos de trayecto.

\subsection{Consideraciones sociales y territoriales sobre la caza en Mallorca y en España}

Mallorca constituye un espacio insular del Mediterráneo occidental con una amplia tradición en la práctica y la gestión cinegética derivada, entre otras cuestiones, de la variedad de especies de caza menor beneficiada por una privilegiada posición geográfica en rutas migratorias, por la diversidad de hábitats y por la presencia de una especie de caza mayor única, la cabra salvaje mallorquina, además de razas autóctonas de perros y modalidades tradicionales exclusivas. Asimismo, la cultura cinegética insular se refuerza, entre otros, con estudios históricos de gran calado (Bover y Rosselló, 2016), generando una terminología lingüística genuina con argots propios según comarcas (Servera Vila, 2006) o plasmándose en el paisaje a través de construcciones populares de piedra en seco específicas para la caza (Aguiló, Castelló, Seguí, Barceló, García y Vidal, 2011; Barceló Adrover y Grimalt Gelabert, 2014).

En términos sociales, el padrón de personas que practican la caza es significativo, 2,11\% de la población total en 2013, y se encuentra distribuido ampliamente por toda la isla. Para el año 2010 (Barceló, 2013), el porcentaje de cazadores sobre la población total es de un 2,21\% en España y de un 1,22\% para el conjunto de Europa. Los valores insulares son semejantes a los nacionales y muy por encima de la media europea, aunque lejos de los registrados en Estados Unidos que en 2011 se sitúa próxima al 4,5\% (U.S. Fish and Wildlife Service, 2011).

En conjunto, el colectivo cinegético es principalmente masculino y con tendencia al envejecimiento por falta de relevo generacional, al igual que ocurre en muchas otras zonas del territorio nacional (Iglesias, 2013; Laborde, 2016).

Los valores referidos no se alejan drásticamente de los presentes en otras comunidades autónomas y territorios europeos. En el caso de Extremadura y en cuanto a los retos de falta de relevo generacional, Rengifo Gallego (2012) propone trabajar para transmitir una imagen asociada de la caza con la conservación entre los grupos más jóvenes de la sociedad. Domina sobremanera el género masculino y el porcentaje de mujeres que practican la caza $(1,68 \%$ ) es similar a los existentes en Francia ( $2 \%$ en 2006) o Italia (<1\% en 2013) y muy distante a los observados en Alemania (10\% en 2012), Austria (7,50\% en 2013) o Reino Unido (6,50\% en 2017), (FACE, 2017). No obstante, en España, según datos recientes el número de mujeres con licencia federativa de la Federación Española de Caza ha aumentado en un 13,79\% entre 2014 y 2015 (Ministerio de Educación, Cultura y Deporte, 2016).

El número de licencias de caza obtenidas por personas foráneas es bajo (<5\%) sobre todo si se compara con Extremadura que en el año 2003 el 18,52\% de las licencias expedidas se correspondían con cazadores de otras comunidades españolas y el 5,80\% eran de extranjeros (Rengifo Gallego, 2008) o Aragón dónde en torno al 30\% de las licencias son para residentes en otras comunidades (El Periódico de Aragón, 2014). Aun así, hay que prestar atención al potencial del turismo cinegético en Mallorca, tanto por cuestiones de exclusividad cinegética (cabra salvaje mallorquina) como por aspectos de localización, accesibilidad, clima y know-how en materia turística. De hecho, el turismo de caza se trata de un segmento de turismo internacional en auge (Rengifo Gallego, 2008) asociado a la mayor movilidad de las personas y a la existencia de una gran variedad de especies cinegéticas en el mundo, al desarrollo de entramados empresariales especializados y a la diversidad de motivaciones ligadas a los desplazamientos (Gunnarsdotter, 2006; Naidoo, Weaver, Diggle, Matongo, Stuart-Hill y Thouless, 2016; Chanteloup, 2016).

Una característica social de la caza en Mallorca compartida con el conjunto de España es la importancia del asociacionismo cinegético. Las sociedades de cazadores de ámbito local constituyen el emblema primigenio de la actividad asociacionista en la isla y se encuentran implantadas en 50 de los 53 municipios de la isla. De hecho, hay municipios que disponen de más de una sociedad de cazadores y hay otra una importante relación entre número de cazadores y existencia de sociedad de cazadores. En materia territorial, los cotos de las sociedades de cazadores tienen en común que son grandes y diversos, pero 
fracturados en cientos y miles de propiedades distintas. El 96,90\% de los terrenos que integran los cotos gestionados por las sociedades de cazadores de ámbito local son privados y sólo el 3,10\% restante son públicos. Estas entidades aglutinan a la mayoría de los cazadores presentes en los municipios (sobre todo de la parte foránea), ejecutan acciones de ordenación y gestión cinegética y canalizan demandas hacia la administración, otras organizaciones cinegéticas o propietarios de tierras. Asimismo, ante la privatización de terrenos de caza, las sociedades de cazadores son el baluarte defensivo de los derechos del cazador modesto, que sin duda es el más abundante en España (Mulero Mendigorri, 1991). En este caso la realidad insular sigue la línea general observada a lo largo del territorio nacional, en dónde se contabilizan más de 6.000 sociedades de cazadores y clubes de caza, cifra muy significativa si tenemos en cuenta que en el estado se sobrepasan los 8.100 municipios.

Aunque la actividad cinegética en Mallorca se encuentra en un marcado retroceso social, continúa manteniendo un ámbito territorial extenso. Como dato comparativo de carácter retrospectivo, para el año 1978 (Brunet Estarellas, 1988) las hectáreas acotadas por licencia de caza, en el conjunto de Baleares eran 11,26 . Se trata de una cifra resultante un $40 \%$ menor de la que aparece para el 2013 , lo que se explica en la actualidad parcialmente por el incremento del terreno vedado, pero sobre todo por la disminución del número de cazadores. En 1978 había, para el conjunto de Baleares, 1.098 cotos que sumaban 271.378 ha vedadas y 24.186 licencias de caza, mientras que para el 2013, sólo en Mallorca, hay 1.466 cotos, $333.018,33$ ha SAC y 21.323 licencias de caza.

El aumento del terreno cinegético resulta más teórico que real, ya que, a pesar del incremento de las hectáreas potencialmente cinegéticas, se ha producido un proceso de ocupación del territorio por actividades urbanas, que dificultan la caza. El medio rural mallorquín ha experimentado un incremento muy notable de construcciones unifamiliares de tipología muy diversa, pero con un patrón de distribución especialmente denso (Binimelis Sebastián 2006, Binimelis Sebastián y Ordinas Garau, 2012). Esta tendencia a la rurubanización ligada a la decadencia de los usos y las actividades agrarias tradicionales, conduce a una merma del espacio apto para la práctica de la caza y/o de la calidad de los acotados, a la multiplicación de zonas de seguridad que limitan la caza con arma de fuego debido a la presencia de caminos, viviendas y otras infraestructuras, a la aparición de nuevos conflictos de intereses, a la introducción de nuevos depredadores y a la destrucción de hábitats. En los espacios rústicos es innegable la supremacía del valor inmobiliario del territorio frente al rédito cinegético, más ahora cuando las viviendas de turismo vacacional se extienden por el interior y se incrementa la demanda extranjera de segundas residencias anuales (tanto en propiedad como en alquiler). Este avance rururbano es un cambio territorial de primer orden que los cazadores deben asumir y definir estrategias de convivencia.

En Mallorca, a diferencia de la mayoría de comunidades autónomas españolas, no existe oferta pública de caza. En términos de propiedad de los terrenos cinegéticos se presenta un fuerte contraste entre la superficie vedada de carácter privado, que es superior al 98\%, y la pública, que no llega al 2\%. En este sentido, parece ser que las sociedades de cazadores y la presencia de terrenos libres común ha suplido la necesidad de crear cotos sociales. En cuanto a las fincas públicas, la Administración se ha decantado prioritariamente por la creación de refugios de caza frente a figuras cinegéticas. Parece que una de las principales razones que pueden explicar esta situación se argumenta teniendo en cuenta criterios de seguridad atendiendo al alto grado de uso público que tienen estos espacios (senderismo, sobre todo).

Además de la ausencia de falta de cotos públicos, Mallorca adolece de una importante limitación de terrenos libres hábiles para la práctica cinegética. Sea como fuere, la reducción de los terrenos libres cazables pone en escena la necesidad administrativa de plantear la habilitación de cotos sociales u otras soluciones, asuntos sobre los que ya está trabajando el Departament de Desenvolupament Local del Consell de Mallorca.

Un análisis estadístico evolutivo a corto plazo sobre espacios cinegéticos y titulares de licencias de caza entre 2009 y la actualidad (Tabla 13) muestra que el número de cotos de caza ha aumentado más de un 6\% (se ha pasado de 1.406 en 2009 a 1.500 en 2018), la superficie acotada ha aumentado un 4,5\% (en 2009 había 268.659,15 ha acotadas y en 2018 hay 280.990,41), los refugios de fauna o espacios no cinegéticos aumentan en un 44\% (de 59 en 2009 pasan a 85 en 2018), la superficie que corresponde a espacios no cinegéticos aumenta en un 32,31\% (las 7.661,24 ha de 2009 son 10.136,74 ha en 2018), los titulares de licencia de caza disminuyen en un $21,01 \%$ (de 20.659 en 2009 se pasa a 16.317 en 2017) y los recargos para la práctica de la caza mayor aumentan un 3,5\% (en 2009 se expidieron 2.601 recargos de caza mayor y en 2016, 2.693). 
Tabla 13. Evolución del número de espacios cinegéticos, ha acotadas, número de espacios no cinegéticos, superficie de los espacios no cinegéticos, número de titulares de licencias de caza y recargos de caza mayor entre 2009 y 2017

\begin{tabular}{|c|c|c|c|c|c|c|}
\hline Año & $\begin{array}{c}\mathbf{N}^{\mathbf{o}} \text { Espacios } \\
\text { cinegéticos }\end{array}$ & $\begin{array}{c}\text { Ha Espacios } \\
\text { cinegéticos }\end{array}$ & $\begin{array}{c}\mathbf{N}^{\mathbf{o}} \text { Espacios } \\
\text { no cinegéticos }\end{array}$ & $\begin{array}{c}\text { Ha Espacios } \\
\text { no cinegéticos }\end{array}$ & $\begin{array}{c}\text { Titulares de } \\
\text { licencia de caza }\end{array}$ & Recargos \\
\hline 2009 & 1.406 & $268.659,15$ & 59 & $7.661,24$ & 20.659 & 2.601 \\
\hline 2010 & 1.415 & $276.142,64$ & 61 & $8.087,53$ & 20.223 & 2.643 \\
\hline 2011 & 1.441 & $278.414,44$ & 64 & $8.104,40$ & 19.370 & 2.641 \\
\hline 2012 & 1.459 & $279.681,24$ & 70 & $8.406,62$ & 18.445 & 2.553 \\
\hline 2013 & 1.466 & $280.276,11$ & 73 & $8.495,60$ & 18.236 & 2.573 \\
\hline 2014 & 1.477 & $279.870,38$ & 73 & $8.566,44$ & 17.999 & 2.557 \\
\hline 2015 & 1.491 & $280.886,18$ & 76 & $8.665,16$ & 17.769 & 2.535 \\
\hline 2016 & 1.504 & $282.892,23$ & 76 & $8.706,06$ & 17.646 & 2.693 \\
\hline 2017 & 1.501 & $282.428,92$ & 78 & $8.741,15$ & 16.317 & SD \\
\hline 2018 & 1.500 & $280.990,41$ & 85 & $10.136,74$ & SD & SD \\
\hline
\end{tabular}

Fuente: Servicio de caza del Departament de Desenvolupament Local del Consell de Mallorca. Elaboración propia

Estos resultados ponen de relieve el constante dinamismo de la actividad cinegética en Mallorca, aunque con desigual evolución entre territorios cinegéticos y personas practicantes. Una lectura detallada de los datos expuestos permite afirmar que el número de espacios acotados aumenta tanto por la creación de nuevos cotos como por segregación de los ya existentes, si bien parece que en los últimos años se alcanza una estabilización e incluso un decrecimiento en favor de los espacios no cinegéticos o refugios de fauna. De hecho, entre 2017 y 2018 se produce la conversión de las fincas públicas del Consell de Mallorca declaradas hasta el momento como zonas de caza controlada en refugios de fauna, lo cual repercute positivamente en el número y extensión de estos últimos.

La recesión continuada de los titulares de licencias de caza puede explicarse a partir de la falta de relevo generacional y del contexto de crisis económica, pero deben tenerse en consideración cuestiones de territoriales como la reducción de los terrenos libres, la falta de cotos sociales, la dificultad de acceder a acciones en cotos particulares a precios asequibles, el aumento de las listas de espera y las condiciones de acceso a las sociedades de cazadores, además del citado incremento de los usos rururbanos y de ocio en las áreas agrarias. Finalmente, la caza mayor mantiene un seguimiento estable y en ligero crecimiento, en paralelo con las tendencias nacionales e internacionales.

En el plano nacional, la caza también experimenta un proceso evolutivo con algunas características muy a la par con las detectadas en Mallorca. La revista especializada en temática cinegética Caza y Safaris (Sanz, 2017), ha publicado un análisis estadístico evolutivo a nivel nacional sobre licencias y tarjetas europeas de armas, licencias de caza y cazadores y sociedades federadas, a partir de datos de los anuarios estadísticos del Ministerio del Interior, de los anuarios de estadística forestal de Ministerio de Agricultura, Alimentación y Medio Ambiente y de la memoria de licencias deportivas del Consejo Superior de Deportes. Los puntos más destacados del estudio son:

- Entre 1994 y 2015, las licencias de armas tipo D (armas largas rayadas para la caza mayor, pasan de

132.618 a 365.868. El incremento es del $175,88 \%$. Durante el mismo período las licencias tipo E (incluye sobretodo escopetas de caza) pasan de 1.821 .846 a 1.043.538. El descenso es del 42,72\%. Las tarjetas europeas de armas (autorización que concede la Dirección General de la Guardia Civil para viajar con armas con destino en la Comunidad Europea) expedidas en 1994 eran 684 y en 2015 son 11.457. El incremento es superior al $1.500 \%$.

- En 1990 el número de licencias de caza es de 1.443.514 y en 2013 es de 848.243. El descenso es del $41,23 \%$.

- Entre el 2000 y el 2015, los cazadores federados pasan de 440.299 a 333.974 y las sociedades federadas de 5.905 a 5.836 . El descenso es del 24,14\% y del 1,16\% respectivamente. Cabe indicar que entre 2001 y 2015, el número de mujeres cazadoras federadas pasa de 568 a 2.178, siendo el incremento del $283,45 \%$.

Analizando los datos de forma global se refleja un acusado descenso del número de practicantes de la actividad cinegética, sobre todo en relación con la caza menor. No obstante, hay un incremento muy 
notorio en lo que se refiere a la caza mayor. Muy destacable es el hecho que el entorno asociacionista se mantiene y que el género femenino, aunque con cifras absolutas modestas, presenta una tendencia alcista. Estos resultados invitan a reflexionar sobre la desigual evolución de la caza menor y mayor en España. A grandes rasgos, mientras que las especies de caza menor son muy sensibles a los efectos de la desagrarización, a los cambios tecnológicos en los agroecosistemas tradicionales y a la pérdida de hábitats, las especies de caza mayor se beneficia del abandono rural y del crecimiento de los espacios forestales. A partir de aquí se plantea otra cuestión relacionada con el apartado socioeconómico de la caza; mientras que, por lo general, la caza menor se lleva a cabo de forma individual o en pequeños grupos, en el ámbito local y con arraigo asociacionista y, en muchos casos, mediante prácticas tradicionales o cosmopolitas que conllevan gastos modestos o moderados, la caza mayor exige grandes extensiones territoriales, una mayor organización, traslados y viajes, equipamiento técnico y, en definitiva, una mayor poder adquisitivo de la persona que practica esta modalidad. Por otra parte, en menos de una década (entre 2014 y 2006), según el MAPAMA las hectáreas que se dedican a la caza en España han aumentado en 4.845.245 lo que viene a ser en torno al 12\% del total, siendo el $87 \%$ de la superficie de España terreno de caza (Redacción revista Jara y Sedal, 2017).

Ante datos como los precedentes, diversos autores especialistas en la geografía cinegética española (Rengifo Gallego, 2008; Martínez Garrido, 2009; Crespo Guerrero, 2017) aluden al fin del boom cinegético, determinado principalmente por el estancamiento y posterior descenso del número de licencias de caza acaecido en España entre mediados de la década de los ochenta y principios de los noventa del siglo pasado.

Lo que sí es cierto es que la práctica cinegética evoluciona constantemente, incluso modelando la propia definición del concepto y avanzando hacia aspectos de sostenibilidad y conservación ambiental, ya que se basa en el aprovechamiento ordenado de un recurso natural renovable como son las especies de caza mayor y menor, la mayoría de las cuales caracterizadas por ser típicamente estrategas de la «r» con dinámicas de reproducción abundantes (Servent, Pont, Arilla y Rocaspana, 2015). En efecto, mientras la mayoría de diccionarios y enciclopedias asocian la muerte de la presa al concepto caza o no se incluyen dentro del turismo cinegético actividades que no conllevan el abatimiento del animal (Rengifo Gallego, 2008), en la actualidad emerge el seguimiento de modalidades, con gran dosis de tradicionalidad, que permiten capturar en vivo las presas y retornarlas al medio (previo estudio o fotografía) o translocarlas a otros lugares. En Baleares, es el caso de la caza de la perdiz con reclam i bagues, la caza del tord a coll o la caza de la cabra con perros y lazos, las cuales capturan vivos a los animales.

Esta evolución, además del envejecimiento de las personas que practican la caza, es debida al rechazo cada vez más extendido por parte de la población. Y es que en términos espaciales la caza consume mucho espacio y de aquí su potencial conflictividad (López Ontiveros, 1994) con otros usos y/o usuarios del medio rural. De hecho, a los ya grandes problemas histórico-filosóficos y a otros de como por ejemplo los conflictos territoriales estrictos, los campesinos frente a forasteros urbanos, el derecho de uso versus derecho de propiedad, los problemas entre cazadores y agricultores, ecologistas o administración definidos por López Ontiveros (1994) cabe mencionar a día de hoy el auge de la rururbanización o la proliferación de corrientes animalistas. De hecho, por encima de estas cuestiones concretas, hay que apuntar el desconocimiento de muchas actividades propiamente rurales debido a la homogeneización de pautas y percepciones distorsionadas por parte de la sociedad urbanita que busca en el medio rural un ámbito idílico, despreciando o rechazando los elementos que no se corresponden con su modelo estereotipado (Moltó Mantero y Hernández Hernández, 2004).

No obstante lo anterior, no se puede obviar la contribución de la actividad cinegética a la conservación y aprovechamiento sostenible de la biodiversidad, la protección de las especies y de los hábitats, la conservación de usos tradicionales de las zonas rurales y el mantenimiento de su patrimonio cultural, así como a la aportación de rentas complementarias a las explotaciones agrarias y a otras actividades relacionadas en el medio rural (Rengifo Gallego y Sánchez Martín, 2016). La Política Agraria Común es un mecanismo de apoyo crucial para la agricultura y el medio rural. En este sentido la Federación de Cazadores Europeos (FACE) y sus miembros están instando a la Comisión Europea a elaborar una PAC más respetuosa con la biodiversidad. Para los intereses de la caza esto se traduce en que debería tener un papel más positivo con respecto a la conservación de las especies de caza menor, que requieren una mayor diversidad de hábitats en los cultivos. Las decisiones a nivel local y sus consecuencias de cara a la biodiversidad deben ser analizadas y decididas en conjunto con la experiencia de agricultores y cazadores 
(Willnegger, 2017). Igualmente, a nivel europeo, la FACE se involucra en la implantación del Plan de Acción y de directivas sobre la naturaleza en general para estimular aún más el papel positivo de los cazadores europeos en la conservación (Scallan, 2017). Caza y conservación deben caminar en el mismo sentido, propiciando la preservación de los hábitats en los que viven las especies de caza, invirtiendo los ingresos derivados por el pago de licencias, tasas o impuestos en el mantenimiento y recuperación de las especies salvajes y haciendo partícipes de los beneficios económicos a los habitantes locales (Rengifo Gallego, 2008).

Retornando a Mallorca, la importancia social y territorial de la actividad cinegética adquiere un valor significativo cuando es dimensionada en comparación con macro magnitudes agrarias. En las Islas Baleares la superficie cultivada representa el 34,3\% de la superficie total; la superficie forestal, el 31,8\%; la zona urbanizada, el 13,3\%; las áreas sin vegetación, el 12,3\%, y otros tipos de vegetación, el 8,3\% (Àrea d'Agricultura i Pesca, Estadística, 2009). En conjunto, más de las 3/4 de la superficie está ocupada por espacios agrarios o forestales, lo cual define un paisaje característico con múltiples externalidades medioambientales positivas, y en Mallorca más del 90\% del territorio es potencialmente susceptible de aprovechamiento cinegético. Adicionalmente, según la Encuesta de Población Activa (EPA), la ocupación en el sector primario en Baleares durante el 2009 fue de 6.650 personas de media, y en el caso de Mallorca, el total de personas trabajadoras afiliadas al sector agro pesquero es de 6.681 lo que representa un $1,7 \%$ del total (Àrea d'Agricultura i Pesca, Estadística, 2009).Comparando datos agrarios con cifras cinegéticas en términos territoriales y humanos, se obtiene que la superficie cinegética es ligeramente superior a la extensión agraria y que el número de cazadores triplica prácticamente el total de personas afiliadas al sector agro pesquero. De este modo, resulta de gran interés considerar el elevado potencial del sector cinegético en el ámbito de la planificación agraria, forestal y ambiental. En este sentido, cabe destacar que el Plan de Desarrollo Rural (PDR) para las Islas Baleares (2014-2020), y que deriva de la Política Agraria Común (PAC), incluye como beneficiarios a los titulares de cotos de derechos cinegéticos en las submedidas 4.4. (apoyo a las inversiones no productivas vinculadas al cumplimiento de objetivos agroambientales y climáticos), 6.2 (ayudas destinadas a la creación de empresas para actividades no agrícolas en zonas rurales) y 6.4 (apoyo a las inversiones en creación y desarrollo de actividades no agrícolas). En cuanto a las condiciones de admisibilidad, los cotos cinegéticos deberán disponer de un plan de gestión de caza y realizar un seguimiento de las poblaciones de aves esteparias y otras especies silvestres protegidas. Los criterios seguidos para incluir la caza en el PDR balear están relacionados con aspectos territoriales y de conservación. De hecho, la extensión del territorio afectado por terrenos cinegéticos, supone la coexistencia sobre la misma base territorial de la actividad agraria y la cinegética, siendo ésta un elemento más de aprovechamiento de las explotaciones agrarias.

Ante la situación actual de la caza y considerando sus múltiples externalidades positivas en términos de conservación ambiental y de desarrollo rural, cabe plantear la introducción de nuevos conceptos en los planteamientos relacionados con la planificación cinegética. Si bien hasta ahora los planes técnicos de caza han estado muy centrados en cuestiones relativas a la gestión territorial y a los recursos cinegéticos de cada coto, cabe plantear la necesidad que incluyan aspectos asociados a la planificación social del colectivo cinegético (formación, relevo generacional, acreditación como gestores / observadores ambientales, etc.), impulsar los certificados de calidad cinegética y promover el avance de los planes técnicos comarcales.

\section{Conclusiones}

La actividad cinegética, a pesar de ser una constante histórica se ve sometida a una continua evolución, lo que requiere de una permanente revisión y actualización de los datos recogidos en las diversas fuentes estadísticas que reflejan su impacto social y territorial, y permiten predecir su futuro.

A la luz de los datos más actuales se aprecia como en la isla de Mallorca el colectivo cinegético se encuentra en un proceso de recesión, disminuyendo su peso demográfico como consecuencia del envejecimiento del mismo, al igual que ocurre en otras comunidades como Extremadura (Rengifo Gallego, 2012) o Cataluña (Mateos, 2014). No obstante, en una parte considerable del territorio insular (los municipios de interior y de montaña, principalmente) prevalece con fuerza y mediante determinadas estrategias de comportamiento como colectivo (un mayor relevo generacional y el impulso a la incorporación de la mujer) se podría evitar la previsible recesión del mismo (Barceló Adrover y Seguí Campaner, 2017). 
De hecho, se constata también a nivel insular el fin del boom cinegético definido para el conjunto en España; disminuyen progresivamente las licencias de caza y se estancan los terrenos cinegéticos (Martínez Garrido, 2009). Es posible que se trate de un reajuste de una sociedad post-turística en respuesta a procesos de mayor calado derivados, entre otros, de la terciarización económica, los cambios en la recreación rural, las nuevas formas de ocio urbano, las tendencias urbanas o la rururbanización (Binimelis Sebastián, 2006).

No obstante, algunos hechos permiten augurar un futuro medianamente optimista al sector venatorio en Mallorca como es el auge que actualmente ha adquirido el turismo cinegético y la caza mayor, asentado en el caso insular sobre unas bases estratégicas que combinan desarrollo rural, conservación de la cabra salvaje mallorquina, aplicación de modelos de gestión de calidad y preservación de modalidades tradicionales únicas (Seguí Campaner, et al., 2014).

En cuanto a la componente territorial de la caza, los espacios cinegéticos de la isla reflejan rasgos alineados con el conjunto de España representados por un elevado porcentaje de superficie acotada. Los cotos son predominantemente privados, dándose una situación casi paradójica, en la que contrasta un notable asociacionismo (con alta presencia de sociedades de cazadores) contrapuesto a una escasa presencia de cotos locales, cotos sociales y zonas de caza controlada, situación similar a otras regiones como Castilla-La Mancha y el conjunto de España (Martínez Garrido, 1991). No obstante, las sociedades de cazadores se erigen en los principales ejes vertebradores sociales y territoriales de la caza en Mallorca, con un potencial de gestión muy destacado en términos ambientales y ecologistas (Fernández, 1986; Mulero Mendigorri, 1991; Gutiérrez, 2013 y Barceló Adrover, Grimalt Gelabert y Binimelis Sebastián, 2015).

En la actualidad, la actuación de la Administración va transformando el uso venatorio del territorio con la progresiva inhabilitación cinegética en terrenos libres y fincas públicas, a menudo como consecuencia de políticas ambientales proteccionistas impulsadas socialmente por una población progresivamente más urbana y desconectada del medio rural y de las actividades tradicionales. En todo caso, también es conveniente evaluar y tener en cuenta el alcance ambiental derivado de la actividad cinegética (Andueza et al., 2018a; Andueza et al., 2018b y Rengifo Gallego, 2016).

Al realizar un análisis integrador de los factores sociales y territoriales de la caza, mediante el cálculo de los índices de superficie susceptible de aprovechamiento cinegético en relación a sus usuarios, la isla de Mallorca se puede considerar como espacio equilibrado en cuanto a titulares de licencia de caza en relación a las hectáreas acotadas. En efecto, se constata en Mallorca la hipótesis planteada inicialmente en la cual se presuponía la existencia de importantes diferencias en cuanto a disponibilidad de espacio cinegético apto entre términos municipales. Se define una línea principal de municipios demandantes y equilibrados (gravitando sobre la capital) sobre el eje de asentamientos y comunicaciones Palma-Alcúdia y que coincide con las comarcas geográficas de Palma y es Raiguer, la cual se complementa con apéndices de demarcaciones equilibradas en sentido norte y sur, además de algunos enclaves dispersos. De hecho, esta distribución muestra ciertos paralelismos con, por ejemplo, el esquema topológico de la antigua red de ferrocarriles de Mallorca (Brunet, 1989) que inicialmente unía Palma e Inca, y posteriormente surgieron ramales hasta Sóller, Santanyí, Felanitx, Manacor, Artà y Sa Pobla. En la periferia o márgenes externos de los municipios demandantes y equilibrados aparecen amplios espacios de municipios ofertantes. Emerge, en base a este reparto territorial, un patrón cinegético centrífugo definido por la evolución urbana de la isla y en el cual entran en juego cuestiones relacionadas con la movilidad. Esto nos permite intuir la existencia en Mallorca de importantes movimientos pendulares entre el lugar de residencia del practicante de la actividad y el espacio cinegético. A lo sumo estos desplazamientos pueden ser de unos 100-120 km, entre ida y vuelta, lo cual es un recorrido modesto en comparación con espacios de caza peninsulares. La estructura radial de carreteras de Mallorca, con centro en Palma, permite buenas conexiones con prácticamente toda isla lo cual, a efectos prácticos, minimiza las desigualdades municipales con cargo a los desplazamientos y se homogeneíza la presión cinegética.

Los datos analizados junto con los recursos existentes y considerando la evolución socioeconómica de Mallorca hacen pronosticar un futuro cambiante de la actividad cinegética con tendencias orientadas a la revitalización de las modalidades tradicionales en la mayoría de espacios acotados, un incremento de la caza mayor, una revalorización de cotos continuos y poco fragmentados, y la necesidad de nuevos planteamientos en la gestión de las sociedades de cazadores, sus dominios territoriales y en la imagen del colectivo (Delibes-Mateos, Caro y Arroyo, 2017). 
A partir de todo lo anterior, la planificación cinegética, no sólo en términos territoriales y de recurso, sino también social, se instituye como herramienta estratégica y de gran calado para abordar los retos actuales de la caza y avanzar hacia planteamientos de calidad (Caro, Delibes-Mateos y Arroyo, 2014).

\section{Agradecimientos}

A Don Mateu Castelló Mas († 2015), a Bartomeu Binimelis Roig (†2016) y a María Adrover Adrover (†2017), por sus grandes enseñanzas sobre naturaleza y medio rural.

Al Departament de Desenvolupament Local del Consell de Mallorca por su apoyo y aportación de datos sociales y territoriales en materia de caza.

Al Dr. Bartomeu Seguí Campaner, Jefe del Servicio de Caza del Consell de Mallorca, por su ayuda y revisión de este artículo.

A la Sra. Antonia Rosselló Oliver, Servicio de Caza del Consell de Mallorca, por su valioso trabajo de recopilación y tabulación de datos estadísticos.

Al personal técnico, administrativo y de vigilancia del Servicio de Caza del Consell de Mallorca, y con el cual hemos trabajado para la redacción de este documento, por su constante implicación en el cometido de su trabajo y colaboración en materia de investigación.

\section{Referencias}

Aguilar, R. y Mayol, J. (1988). Evolució i distribució recent del nombre de caçadors a les Balears. Treballs de geografia, 40, 61-65. Recuperado de https://www.raco.cat/index.php/TreballsGeografia/article/ view/104051

Aguiló, J. A., Castelló, M., Seguí, B., Barceló, A., García, A i Vidal, J. (2011). Caça i pedra en sec a Mallorca. En Reynes, A. (coord.). V Trobada d'estudi per a la preservació del patrimoni de pedra en sec als Països Catalans, 2009. Recuperado de https://www.conselldemallorca.cat/media/42228/V_Trobada.pdf

Andueza, A., Lambarri, M., Urda, V., Prieto, I., Villanueva, L.F. y Sánchez García, C. (2018a). Evaluación del impacto económico y social de la caza en Castilla - La Mancha 2016. Recuperado de https://www. fundacionartemisan.com/wp-content/uploads/2018/02/Informe-Caza-Castilla-La-Mancha-DeloitteArtemisan.pdf

Andueza, A., Lambarri, M., Urda, V., Prieto, I., Villanueva, L.F. y Sánchez García, C. (2018b). Evaluación del impacto económico y social de la caza en España. Recuperado de https://www.fundacionartemisan. com/wp-content/uploads/2018/05/ESTUDIO-COMPLETO-ESPA\%C3\%91A.pdf

Àrea d'Agricultura i Pesca. Estadística. (2009). Estadístiques bàsiques de l'agricultura, la ramaderia i la pesca a les Illes Balears. Govern de les Illes Balears: Conselleria de Presidència.

Barceló Adrover, A. (2009). La caça a Mallorca. Mallorca: Conselleria de Medi Ambient del Govern de les Illes Balears.

Barceló Adrover, A. (2013). Història i Geografia de la Caça. En A. Barceló (Ed.), La caça i la cultura cinegètica de Menorca (pp. 12-65). Mallorca.

Barceló Adrover, A. (2015a). Caça, territori i societat a Mallorca (Tesis doctoral). Universitat de les Illes Balears, Palma de Mallorca.

Barceló Adrover, A. (2015b). La Caça a Menorca (2): Les espècies de caça a Menorca, terrenys de caça i caçadors. Menorca: Col-lectiu Folklòric de Ciutadella (núm.104).

Barceló Adrover, A. y Grimalt Gelabert, M. (2014). La huella cinegética en Mallorca. Piedra en seco y gestión de la caza. En D. Pavón Gamero, A. Ribas Palom, S. Ricart Casadevall, A. Roca Torrent, I. Salamaña Serra y C. Tous de Sousa (Eds)., XVII Coloquio de Geografía Rural. Revalorizando el espacio rural: leer el pasado para ganar el futuro (pp. 745-758). Recuperado de https://parqueagrariofuenlabrada.es/wpcontent/uploads/2014/09/XVII-Coloquio-de-Geografia-Rural.pdf

Barceló Adrover, A. y Seguí Campaner, B. (2017). Anàlisi dels aspectes socials de la caça a Mallorca: distribució territorial, anàlisi per edats i gèneres, tipologies de llicències i comparatives. Boll. Soc. Hist. Nat. Balears, 60, 65-89. Recuperado de https://www.raco.cat/index.php/BolletiSHNBalears/article/ view/338452 
Barceló Adrover, A., Grimalt Gelabert, M. y Binimelis Sebastián, J. (2015). Implicaciones territoriales, sociales y ambientales de las sociedades de cazadores locales en Mallorca. En J. de la Riva, P. Ibarra, R. Montorio, y M. Rodrigues, (Eds.), XXIV Congreso de la Asociación Española de Geógrafos. Análisis espacial y representación geográfica: innovación y aplicación (pp 1543-1552). Recuperado de http:// congresoage.unizar.es/eBook/trabajos/163_Barcelo\%20Adrover.pdf

Barceló Adrover, A., Binimelis Sebastián, J. y Grimalt Gelabert, M. (2016). Caracterización del perfil social y territorial del cazador mallorquín. En A.R. Ruíz Pulpón, M.A. Serrano de la Cruz SantosOlmo y J. Plaza Tabasco (Coords), Treinta años de Política Agraria Común en España (pp. 496-511). Recuperado de https://dialnet.unirioja.es/servlet/articulo? codigo=6274404

Barceló Adrover, A., Seguí Campaner, B. y Rengifo Gallego, J.I. (2017). La caza de la cabra salvaje mallorquina en el contexto del turismo cinegético. Ería, 37(2), 233-252. https://doi.org/10.17811/ er.2.2017.233-252

Barceló Adrover, A., Grimalt Gelabert, M. y Binimelis Sebastián, J. (2017). Análisis bibliométrico de los estudios geográficos de la caza en España (1978-2015). Boletín de la Asociación de Geógrafos Españoles, 74, 301-332. http://dx.doi.org/10.21138/bage.2456

Bernard Danzberger, J. (2009). 56 millones de cazadores. Trofeo.

Binimelis Sebastiàn, J. (2006). La difusión residencial en el espacio rural de la isla de Mallorca en la década de los noventa. Nuevas aportaciones para una correcta interpretación del llamado "tercer boom" turístico. Scripta Nova. Revista electrónica de geografía y ciencias sociales, X, 225. Recuperado de http://revistes.ub.edu/index.php/ScriptaNova/article/view/1059

Binimelis Sebastián, J. y Ordinas Garau, A. (2012). Paisatge i canvi territorial en el món rural de les Illes Balears. Territoris, 8, 11-28. Recuperado de https://www.raco.cat/index.php/Territoris/article/ view/259750

Bover Pujol, J. y Rosselló Vaquer, R. (2016). La caça i els cans a les Balears (segles XIII-XIX). Monografies de la Societat d'Història Natural de les Balears, 24. Mallorca: Consell de Mallorca. Departament de Desenvolupament Local.

Brunet Estarellas, P. J. (1978). Aspectes geogràfics i socials de la caça i dels vedats a Mallorca. Treballs de geografia, 35, 25-34. Recuperado de http://ibdigital.uib.es/greenstone/collect/treballsGeografiaVolums/ index/assoc/Treballs/_de_Geog/rafia_19/78v35.dir/Treballs de Geografia_1978v35.pdf

Brunet Estarellas, P.J. (1989). La red ferroviaria de Mallorca y su incidencia en el desarrollo insular. Treballs de geografia, 42, 49-55. Recuperado de http://ibdigital.uib.es/greenstone/collect/treballsGeografia/ index/assoc/Treballs/_de_Geog/rafia_19/78v35p02.dir/Treballs_de_Geografia_1978v35p025.pdf

Canton du Valais. Statistiques chasse. Recuperado de https://www.vs.ch/web/scpf/statistique-chasse.

Caro, J., Delibes-Mateos, M. y Arroyo, B. (2014). La gestión cinegética y la conservación de especies. Ambienta, 108, 68-79. Recuperado de http://www.revistaambienta.es/WebAmbienta/marm/Dinamicas/ secciones/articulos/Caro.htm

Cecilia Gómez, J.A. y Martínez Garrido, E. (1986). Manchas de Caza Mayor. Madrid: Ediciones el Viso.

Chanteloup, L. (2016). Du tourisme de chasse au tourisme d'observation, l'expérience touristique de la faune sauvage - l'exemple de la réserve faunique de Matane (Québec). Téoros: Revue de recherche en tourisme, 32(1), 17-26. http://dx.doi.org/10.7202/1036650ar

Crespo Guerrero, J.M. (2013). La caza mayor en la provincia de Jaén (España) antes de la Ley 1/1970. Análisis territorial de un recurso natural (Tesis doctoral, Departamento de Antropología, Geografía e Historia, Facultad de Humanidades y Ciencias de la Educación, Universidad de Jaén, Jaén). Recuperado de http://ruja.ujaen.es/jspui/handle/10953/509

Crespo Guerrero, J.M. (2017). Apuntes sobre la política cinegética franquista (1939-1975). En Sociedad Española de Ciencias Forestales. Gestión del monte: servicios ambientales y bioeconomía. $7^{\circ}$ Congreso Forestal Español. Plasencia, Cáceres, Extremadura. Recuperado de http://7cfe.congresoforestal.es/ content/apuntes-sobre-la-politica-cinegetica-franquista-1939-1975

Decreto 72/2004, de 16 de julio, por el cual se regulan los planes técnicosde caza y los refugios de caza en las Islas Baleares. BOIB, núm. 102 de 22-07-2004, pp. 29-32. 
Delibes-Mateos, M., Caro, J. y Arroyo, B. (2017). Funciones y valoraciones de la caza y su gestión en España: estudios científicos sobre el colectivo cinegético. Arbor, 193 (786), a414. http://dx.doi. org/10.3989/arbor.2017.786n4003

El Periódico de Aragón (10 de noviembre de 2014). El 30\% de las licencias de caza de Aragón son de fuera. Recuperado de http://www.elperiodicodearagon.com/noticias/aragon/30-licencias-caza-aragon-sonfuera_983228.html

Econométrica Investigación Social, S.L. (2009). Estudio socioeconómico sobre a caza e o perfil do cazador en Galicia. Observatorio de Caza, Federación Galega de Caza, Consellería do Medio Rural - Xunta de Galicia, Fondo Social Europeo - Unión Europea. Recuperado de https://www.federaciongalegadecaza. com/Observatorio/Resumo.Estudio.Socioeconomico.pdf

Federation of Associations for Hunting and Conservation of the EU (FACE) (2010). Census of the number of hunters in Europe. Sep. 2010. Recuperado de https://www.face.eu

Federation of Associations for Hunting and Conservation of the EU (FACE) (2017). Proportion of women hunters in different European countries. Recuperado de http://www.face.eu/sites/default/files/ attachments/face_female_hunters_in_europe.pdf

Fernández, F. (1986). Las sociedades de cazadores en Asturias. Un ejemplo de las estrategias para la defensa del espacio rural de la invasión urbana. Ería, 10, 143-145. Recuperado de https://dialnet. unirioja.es/servlet/articulo? codigo $=34659$

Fundación Caza sostenible y biodiversidad (FUNCASBIOD) (2016). El impacto socioeconómico de la actividad cinegética vasca. País Vasco: Departamento de desarrollo económico y competitividad Gobierno Vasco, Desarrollo rural, litoral y alimentario - HAZI. Recuperado de http://www.nasdap. ejgv.euskadi.eus/contenidos/nota_prensa/estudio_socioeconomico_caza/es_def/adjuntos/ESTUDIO_ IMPACTO_CINEGETICO_CAE.pdf

Garrido Martín, J. L. (2012). La caza. Sector económico. Valoración por subsectores. Madrid: FEDENCA EEC. Recuperado de https://www.fecaza.com/images/stories/CAZA_Sector_economico.pdf

González Arenas, J., Arias de Reyna Martínez, L. M. y Ruiz Avilés, P. (2004). La actividad cinegética en Córdoba. Córdoba: Diputación de Córdoba.

Gunnarsdotter, Y. (2006). Hunting tourism as ecotourism: conflicts and opportunities. Ecotourism in Scandinavia: Lessons in Theory and Practice, 172-198. https://doi.org/10.1079/9781845931346.0178

Gutiérrez, J. E. (2013). El potencial de las sociedades de cazadores como herramienta de conservación en España. Ecosistemas, 22(2), 104-106. https://doi.org/10.7818/ECOS.2013.22-2.15

Iglesias, M.J. (20 de febrero de 2013). Tiro de gracia a la caza. La Nueva España. Recuperado de http:// www.lne.es/asturama/2013/02/20/tiro-gracia-caza/1371368.html

Instituto de Estadística de las Islas Baleares (IBESTAT) (2017). Población. Recuperado de https://ibestat. caib.es/ibestat/estadistiques/poblacio

Laborde, A. (15 de noviembre de 2016). El cazador se hace viejo. El País. Recuperado de https://politica. elpais.com/politica/2016/11/15/actualidad/1479208214_519372.html

Ley 7/1985, de 2 de abril, Reguladora de les Bases del Régimen Local. BOE núm. 80. 03/04/1985, pp. 8.945-8.964.

Ley 42/2007, de 13 de diciembre, del patrimonio natural y de la biodiversidad. BOE núm. 299, 14/12/2007, pp. 51.275-51.327.

Ley 6/2006, de 12 de abril, balear de caza y pesca fluvial. BOIB, núm. 61, 27/04/2006, pp. 4-23.

López Ontiveros, A. (1981). El desarrollo reciente de la caza en España. En Supervivencia de la Montaña. Actas del coloquio Hispano - Francés sobre las Áreas de Montaña, (pp.271-297). Madrid: Ministerio de Agricultura y Ministère de l'Environnement et du Cadre deVie.

López Ontiveros, A. (1991). Algunos aspectos de la evolución de la caza en España. Agricultura y Sociedad, $58,13-51$.

López Ontiveros, A. (1992). La investigación sobre la actividad cinegética en España: Estado de la cuestión. En VI Coloquio de Geografía Rural. Ponencias (pp. 145-188). Departamento de Geografía, Universidad de Madrid, Madrid. 
López Ontiveros, A. (1994). Caza, actividad agraria y geografía en España. Documents d’Anàlisi Geogràfica, 24, 111-130. Recuperado de https://www.raco.cat/index.php/DocumentsAnalisi/article/view/41616

López Ontiveros, A. y García Verdugo, F. R. (1991). Geografía de la Caza en España. Agricultura y Sociedad, 58, 81-112. Recuperado de https://helvia.uco.es/bitstream/handle/10396/5587/a058_03. pdf? sequence $=1$

Lluch i Dubon, F. D. (1997). Geografia de les Illes Balears. Palma: Lleonard Muntaner editor.

Marsal Caselles, P.J. y Porta Josa, E. (2001). Estudi de la caça i alternatives de gestió cinegètica a la serra de Castelltallat. En Agencia de Desenvolupament Forestal. Gestió Forestal. Gestió associada de boscos privats i estudis tècnics de les zones cremades 1994-1998 (pp 127-147). Dossier 2.

Martínez Garrido, E. (1991). La geografía de la caza en Castilla-La Mancha. Agricultura y Sociedad, 58, 263-293. Recuperado de https://www.mapa.gob.es/ministerio/pags/biblioteca/revistas/pdf_ays/ a058_10.pdf

Martínez Garrido, E. (2009). Visiones territoriales del boom cinegético español, 1970-1989. Boletín de la Asociación Española de Geógrafos, 51, 325-351. Recuperado de https://www.age-geografia.es/ojs/index. php/bage/article/view/1143

Martinez-Jauregui, M., Arenas, C., y Herruzo, A. C. (2011). Understanding long-term hunting statistics: the case of Spain (1972-2007). Forest Systems, 2011, 20(1), 139-150. https://doi.org/10.5424/ $\underline{\text { fs/2011201-10394 }}$

Mateos, R. (27 de julio de 2014). La falta de cazadores lleva a la Generalitat a estudiar su profesionalización. La Vanguardia. Recuperado de https://www.lavanguardia.com/vida/20140727/54411899935/ la-falta-de-cazadores-lleva-a-la-generalitat-a-estudiar-su-profesionalizacion.html

Metra S. (1985). Turismo Cinegético en España. Madrid: Secretaría General de Turismo, Subdirección General de Infraestructura Turística.

Ministerio de Agricultura y Pesca, Alimentación y Medio Ambiente (MAPAMA) (2013). Estadística Anual de Caza. Recuperado de http://www.mapama.gob.es/es/desarrollo-rural/estadisticas/Est_Anual_Caza. $\underline{\operatorname{aspx}}$

Ministerio de Educación, Cultura y Deporte (2016). Anuario de Estadísticas Deportivas 2016. Recuperado de https://www.mecd.gob.es/servicios-al-ciudadano-mecd/estadisticas/deporte/anuario-deporte.html

Moltó Mantero, E. y Hernández Hernández, M. (2004). La funcionalidad de los medios rurales en las sociedades urbanas. Investigaciones geográficas, 34, 63-76. https://doi.org/10.14198/INGEO2004.34.06

Monge Gómez, J. (2012). La caza en el País Vasco. Foresta, 55, especial País Vasco-Euskadi. Recuperado de http://www.redforesta.com/wp-content/uploads/2012/10/GF2-La-caza-en-el-Pais-Vasco.pdf

Mulero Mendigorri, A. (1991). La organización local de la caza en España. Una aproximación geográfica. Agricultura y Sociedad, 58, 187-213. Recuperado de https://helvia.uco.es/bitstream/handle/10396/5619/ a058_07.pdf? sequence $=1$ \&isAllowed $=\mathrm{y}$

Mulero Mendigorri, A. (1995). Espacios rurales de ocio. Significado general y análisisen la Sierra Morena cordobesa. Madrid: Ministerio de Agricultura, Pesca y Alimentación.

Murray Mas, I. (2012). Geografies del capitalisme balear: poder, metabolisme socioeconòmic i petjada ecològica d'una superpotència turística (Tesis doctoral, Departament de Ciències de la Terra, Universitat de les Illes Balears, Palma de Mallorca). Recuperado de https://www.tesisenred.net/handle/10803/104203

Naidoo, R., Weaver, L. C., Diggle, R. W., Matongo, G., Stuart-Hill, G. \& Thouless, C. (2016). Complementary benefits of tourism and hunting to communal conservancies in Namibia. Conservation Biology, 30(3), 628-638. https://doi.org/10.1111/cobi.12643

Pinet, J.M. (1993). Les chasseurs de France. Paris: Union nationale des Fédérations départementales des chasseurs; Institut national agronomique Paris-Grignon, Laboratoire de la faune sauvage.

Pons Múñoz, J. M. (1995). La caza en Menorca. Menorca: Setmanaris i Revistes.

Redacción revista Jara y Sedal (18 de septiembre de 2017). El 87\% de la superficie de España es terreno de caza. Jara y Sedal. Recuperado de http://revistajaraysedal.es/espana-terreno-de-caza/

Rengifo Gallego, J. I. y Sánchez Martín, J.M. (2016). Caza y Espacios Naturales Protegidos en Extremadura. Investigaciones Geográficas, 65, 57-73. https://doi.org/10.14198/INGEO2016.65.04 
Rengifo Gallego, J. I. (2009). La oferta de caza en España en el contexto del turismo cinegético internacional: las especies de caza mayor. Ería (78-79), 53-68. Recuperado de https://www.unioviedo. es/reunido/index.php/RCG/article/view/1637

Rengifo Gallego, J. I. (2012). Evaluación de la actividad cinegética en Extremadura en los albores del siglo XXI: Retos a corto y medio plazo. Estudios geográficos, 73(272), 189-214. https://doi.org/10.3989/ estgeogr.201207

Rengifo Gallego, J.I. (2008). Un segmento del turismo internacional en auge: el turismo de caza. Cuadernos de turismo, 22, 187-210. Recuperado de http://revistas.um.es/turismo/article/view/48181

Sanz, A. (2017). ¿Nos quedamos sin morraleros? Algunas estadísticas al respecto. Caza y Safaris, 14-19, 390.

Seguí Campaner, B., Sanz Rueda, A., Barceló Adrover, A., García Amengual, A., Santandreu Jaume, J. y Vidal Fueris, J. (2014). Boc Balear, cuatro milenios de historia, diez años de homologación. Mallorca: Departament de Medi Ambient, Consell de Mallorca.

Scallan, D. (2017). Plan de Acción Europeo. Naturaleza, población y economía. Jara y Sedal, 188, 34.

Serrano García, B. (2005). Caza y naturaleza en Monfragüe. Mancomunidad de Monfragüe. El periódico de Extremadura.

Servent, A., Pont, J., Arilla, M. y Rocaspana, R. (2015). Control y vigilancia del aprovechamiento de los recursos cinegéticos y piscícolas. Madrid: Federación de Servicios a la Ciudadanía de CCOO. Ediciones GPS.

Servera Vila, J. I. (2006). L'argot dels caçadors de la contrada de Campos. En J. Massot (coord.) Estudis de Llengua i literatura catalanes (pp. 279-307). Barcelona: Publicacions de l'Abadia de Monserrat.

U.S. Fish and Wildlife Service (2011). National Survey of Fishing, Hunting and Wildlife-Associated Recreation. Recuperado de https://www.census.gov/prod/2012pubs/fhw11-nat.pdf

Willnegger, L. (2017). La contribución de los cazadores a una nueva política agrícola europea. Jara y Sedal, 187, 50. 